\title{
A method for aggregating external operating conditions in multi-generation system optimization models
}

Lythcke-Jørgensen, Christoffer Ernst; Münster, Marie; Ensinas, Adriano Viana; Haglind, Fredrik

Published in:

Applied Energy

Link to article, DOI:

10.1016/j.apenergy.2015.12.050

Publication date:

2016

Document Version

Peer reviewed version

Link back to DTU Orbit

Citation (APA):

Lythcke-Jørgensen, C. E., Münster, M., Ensinas, A. V., \& Haglind, F. (2016). A method for aggregating external operating conditions in multi-generation system optimization models. Applied Energy, 166, 59-75.

https://doi.org/10.1016/j.apenergy.2015.12.050

\section{General rights}

Copyright and moral rights for the publications made accessible in the public portal are retained by the authors and/or other copyright owners and it is a condition of accessing publications that users recognise and abide by the legal requirements associated with these rights.

- Users may download and print one copy of any publication from the public portal for the purpose of private study or research.

- You may not further distribute the material or use it for any profit-making activity or commercial gain

- You may freely distribute the URL identifying the publication in the public portal 


\section{A method for aggregating external}

2 operating conditions in multi-generation

3 plant optimization models

4

5

Adriano Viana Ensinas $^{a}$, Fredrik Haglind ${ }^{b}$, Marie Münster ${ }^{c}$, Christoffer Lythcke-Jørgensen ${ }^{b *}$

a École Polytechnique Fédérale de Lausanne, Industrial Process and Energy Systems Engineering, Rue de I'Industrie 17, Case Postale 440, CH-1951 Sion

${ }^{\mathrm{b}}$ Technical University of Denmark, Mechanical Engineering, Nils Koppels Allé 403, DK-2800 Kgs. Lyngby

${ }^{\text {c } T e c h n i c a l ~ U n i v e r s i t y ~ o f ~ D e n m a r k, ~ M a n a g e m e n t ~ E n g i n e e r i n g, ~ P r o d u k t i o n s t o r v e t ~ 424, ~ D K-2800 ~ K g s . ~ L y n g b y ~}$

* Corresponding author. +45 304272 00. Email: celjo@mek.dtu.dk.

\section{Abstract}

This paper presents a novel, simple method for reducing external operating condition datasets to be used in multi-generation plant optimization models. The method, called the Characteristic Operating Pattern (CHOP) method, is a visually-based aggregation method that clusters reference data based on parameter values rather than time of occurrence, thereby preserving important information on short-term relations between the relevant operating parameters. This is opposed to commonly used methods where data are averaged over chronological periods (months or years), and extreme conditions are hidden in the averaged values.

The CHOP method is tested in a case study where the operation of a fictive Danish combined heat and power plant is optimized over a historical 5-year period. The optimization model is solved using the full external operating condition dataset, a reduced dataset obtained using the CHOP method, a monthlyaveraged dataset, a yearly-averaged dataset, and a seasonal peak/off-peak averaged dataset. The 
economic result obtained using the CHOP-reduced dataset is significantly more accurate than that obtained using any of the other reduced datasets, while the calculation time is similar to those obtained using the monthly averaged and seasonal peak/off-peak averaged datasets. The outcomes of the study suggest that the $\mathrm{CHOP}$ method is advantageous compared to chronology-averaging methods in reducing external operating condition datasets to be used in the design optimization models of flexible multi-generation plants.

Data aggregation; flexibility; multi-generation; operation optimization; polygeneration.

30

31

32

$33 C_{v}$

$34 \quad c$

$35 D$

$36 \quad F$

$37 \quad N$

$38 n$

390

$40 \quad P$

$41 \quad p$

$42 Q$

$43 \quad T$

$44 t$

\section{Nomenclature}

\section{Latin letters}

C Cost [Euro]

$C_{v} \quad$ Power-to-heat production ratio [-]

Specific cost [Euro/MWh]

Dataset

Fuel consumption [MWh]

Number of characteristic parameter intervals

\section{$45 \quad$ Greek letters}

$46 \alpha$

Back-pressure ratio [-] 


\begin{tabular}{|c|c|c|}
\hline 47 & $\lambda$ & Load [-] \\
\hline 48 & $\sigma$ & Standard deviation [-] \\
\hline 49 & Subscripts & \\
\hline 50 & $a a$ & Annually averaged \\
\hline 51 & $i$ & Characteristic parameter interval index \\
\hline 52 & $j$ & Data point index \\
\hline 53 & $k$ & EOC parameter index \\
\hline 54 & $l$ & CHOP group index \\
\hline 55 & $m a$ & Monthly averaged \\
\hline 56 & pot & Potential \\
\hline 57 & $s p$ & Seasonal peak/off-peak averaged \\
\hline 58 & Superscripts & \\
\hline 59 & * & Linearized \\
\hline 60 & Abbreviations & \\
\hline 61 & $\mathrm{CHOP}$ & Characteristic operating pattern \\
\hline 62 & $\mathrm{CHP}$ & Combined heat and power \\
\hline 63 & EOC & External operating condition \\
\hline 64 & FMG & Flexible multi-generation plant \\
\hline
\end{tabular}

\section{1. Introduction}

66 Large-scale integration of intermittent renewable energy sources (solar, wind, tidal and wave) in the energy

67 system imposes a demand for production-consumption balancing [1]. Flexible multi-generation plants

68 (FMGs), here defined as flexibly operating facilities integrating the production of two or more energy

69 services (power, heating, cooling, fuels etc.), may provide such balancing operation [2]. Furthermore, FMGs

70 based on biomass may achieve high aggregated biomass conversion efficiencies through process

71 integration [3], which is of crucial importance in sustainable energy systems as the biomass resource is 
limited on a global level [4] [5]. Such process integration advantages may further be used for providing sustainable fuel and energy services in FMGs at competitive prices [6] [7] [8], thereby integrating various layers of the energy system. The development of efficient biomass-processing FMGs may therefore be seen as an integral part of the transition towards a smart energy system based on renewable energy sources [9] [10].

The design optimization of FMG concepts includes such challenges as synthesising processes from multiple technological alternatives, facility and process dimensioning, process integration, feedstock market-impacts, operation optimization etc. In addition to this, a principal challenge is to optimize design and operational performance with respect to hourly fluctuations as well as long-term changes in demands and prices of various energy products. In principle, these data could be obtained by implementing a detailed energy system model [11] in the design optimization model, but the required data sampling, modelling, and computational effort can be prohibitive. It is therefore common to include external operating conditions (EOCs) that are hardly influenced by plant operation, such as fuel price, heating demand etc., as fixed parameters in multi-period design optimization models. In a case study of a thermal energy system, Hindsberger and Ravn [12] demonstrated that robust results can be obtained by using fixed EOC datasets when external conditions are little affected by system operation.

A fundamental issue in mathematical optimization models is the trade-off between level of detail and ease of solving the model. As the complexity of multi-period optimization problems increases significantly with the number of periods defined [13], it is desirable to reduce the number of period datasets without plummeting result accuracy. One approach to reducing the number of periods is to average EOC parameter values over chronological time-periods. Among averaging methods, the simplest is to average the EOCs over the lifetime of the plant (e.g. Ahmadi et al. [14], Gassner and Maréchal [15], and Chen et al. [16]). A related method is to assume annually static operating conditions, but defining each year as a period to allow for year-to-year variations caused by general energy system developments (e.g. Gerogiorgos et al. [17], and Liu et al. [18] [19]). Another method is to consider monthly average values for one key operating 
parameter and static conditions for all other (e.g. Fazlollahi et al. [20] [21]). A more detailed approach is to consider monthly averaged EOC parameter values in a first-step optimization model, and then conduct detailed hour-wise operation optimization in a sequential step for the most promising designs (e.g. RubioMaya et al. [22] and Uche et al. [23]). However, neither monthly- nor annually-averaged operating parameter values provide information on short-term relations and variations between various operating conditions. While it may be acceptable to neglect this information for static operating facilities, it can be critical to the economy and thermodynamic performance of flexible facilities such as combined heat and power (CHP) plants [24] and FMGs [25] [26]. Failing to consider short-term relations between relevant operating parameters may lead to sub-optimal solutions in the design optimization of FMGs [27].

One approach to reduce energy system data while maintaining details on hourly parameter relations is to represent each year by a small number of typical time-periods. Another approach is to define a number of characteristic periods, like peak-demand and off-peak-demand periods in each of the four seasons (e.g. Chen et al. [2] [28]) or typical demand days for each month based on monthly average parameter values (e.g. Mavrotas et al. [29]).These approaches rely on the assumption that operating conditions and energy demands are linked and cyclic over the seasons, an assumption that may prove inaccurate in energy systems in transition and with large shares of intermittent renewable energy production [1]. To overcome the assumption of cyclic behavior, several studies propose application of cluster analysis to identify typical periods that can be repeated in order to approximate the annual cumulative curves. Ortiga et al. [30] proposed a graphical method for selecting a few typical days that can be used for representing the annual cumulative heating and cooling demand curves. Domínguez-Muñoz et al. [31] and Fazlollahi et al. [32] used a partitional clustering analysis method, the $k$-Mediods method, to create $k$ typical periods. However, such approaches may hide information on peak and extreme operating conditions and lead to significant errors on peak operation performance, as also reported by Fazlollahi et al. [32] in two illustrative examples. In order to overcome these drawbacks, the duration of the typical periods may be extended to several consecutive days or even weeks (e.g. Hedegaard and Münster [33]). However, this approach increases the 
computational effort significantly, thereby counteracting the initial ambition of reducing the number of period datasets. Instead, Bungener et al. [34] proposed a method that applied an evolutionary multiobjective optimization algorithm for identifying $n$ sequential periods representing typical operations for an industrial cluster with the aim of minimizing standard deviation and, at the same time, maintain information on extreme operating conditions. Nemet et al. [35] presented a similar method for aggregating continuous thermal energy production and demand into sequential periods. They presented an MILP model for determining the number and duration of the periods required to obtain a certain level of accuracy over the aggregation. Karlsson et al. [36] proposed a simple method, called the TimeSlicesTool, which sorts annual operating points into three groups for critical combinations of operating characteristics and one group for all other operating points. This was done for work and non-work days in each of the four seasons, resulting in 32 groups. A drawback of this method is the fact that only information on extreme conditions is sustained, while detailed information on frequently occurring operating patterns is lost.

The present paper proposes a novel and simple aggregation-based method for reducing EOC datasets in optimization models. The method, named Characteristic Operating Pattern (CHOP) method, is tailored for reducing EOC datasets with non-cyclic behaviour for FMG optimization models, but it may be used for reducing similar datasets for any facility operating in multiple energy markets. In the CHOP method, EOC data points are clustered in a number of $\mathrm{CHOP}$ groups based on operating condition characteristics rather than on time chronology. The method thereby yields a reduction in calculation times similar to those of averaging methods ( [14] [15] [16] [17] [18] [19] [20] [21] [22] [23]) while maintaining information on shortterm relations and variations between relevant operating parameters, leading to more accurate solutions. Another advantage of the CHOP method is the fact that all initial EOC data are included in the reduced dataset, as opposed to typical time-period approaches ( [28] [29] [30] [31] [32] [33]) where EOC datasets are sought represented by a limited number of periods. Furthermore, the $\mathrm{CHOP}$ method provides a possibility for including data on long-term energy system development without de facto increasing the number of periods, as opposed to several of the previously described methods ( [17] [18] [19] [20] [21] [22] 

al. [27].

In this paper, the structure and contents of the CHOP method are described in detail in Section 2, where an example is given to demonstrate the use of the method. In Section 3, a simple operation optimization model of a CHP plant is developed, and the model is solved using various reduced EOC datasets to compare the performance of the CHOP method to other common methods. Furthermore, a posteriori error analysis is applied to assess the quality of the results obtained. In section 4 advantages and drawbacks of the CHOP method are discussed and a conclusion of the study is given in Section 5. Various reduced EOC datasets are provided in the Appendix.

\section{The Characteristic Operating Pattern method}

The Characteristic Operating Pattern (CHOP) method is an original graphic-based data aggregation method for reducing external operating condition (EOC) datasets. The method assumes quasi-static operation and is applicable on datasets in the form of operating points $O_{j}$, with each point being characterised by a time of occurrence $T_{j}$, a duration $t_{j-}{ }^{1}$, and a number of operating condition parameters $\bar{p}_{j}$.

$$
O_{j}=\left\{T_{j}, t_{j}, \overline{p_{J}}\right\}
$$

In the CHOP method, EOC data points are clustered in groups based on data characteristics rather than the time of occurrence, as opposed to time-chronological averaging methods [ [14] [15] [16] [17] [18] [19] [20] [21] [22] [23]]. The clustered groups, called CHOP groups, are introduced as weighted periods in multiperiod optimization models. A principal sketch of the data aggregation principle applied in the CHOP method is presented in Figure 1. Dynamics cannot be considered in operation optimization models applying CHOP-reduced datasets as information on time chronology is lost.

Two overall procedures are associated with the CHOP method: The CHOP data aggregation method, and error analysis. The CHOP data aggregation method, which is the core of the method, consists of three principal steps:

\footnotetext{
${ }^{1} t_{O_{j}}=1 \mathrm{~h}$ is commonly used when working with power markets [37], but other values of $t_{j}$ may be used as well.
} 
1. Entity selection: Identification of relevant EOC parameters

2. Clustering criteria: Definition of characteristic parameter intervals

3. Cluster procedure: Establishment of $\mathrm{CHOP}$ groups

174

175

As it is desirable to estimate the quality of the results obtained using the reduced dataset, error analysis is an integral part of the CHOP method. Within the framework presented here, one a priori and two $a$ posteriori analyses are suggested, but others may relevant as well.

1. A priori: Evaluate the standard deviation of parameters in $\mathrm{CHOP}$ groups

2. A posteriori: Evaluate the quality of the applied datapoint clustering. Analyse the errors made by neglecting dynamic constraints.

Both a priori and a posteriori error analyses may yield results necessitating reconfiguration of the data aggregation analysis. The overall CHOP method procedure is illustrated in Figure 2.

Next, the contents of the CHOP data aggregation analysis and suggestions for error analyses are presented. The method is illustrated by an example, in which a historical 5-year EOC dataset for a fictive local extraction-based combined heat and power (CHP) plant located in West Denmark is reduced using the method. A principal sketch of the CHP plant is shown in Figure 3.

\subsection{CHOP data aggregation method}

\subsubsection{Entity selection}

The first step in the CHOP data aggregation analysis is to select data entities for clustering. This implies 1) identification of EOC parameters $p_{k}$ for the plant of interest, and 2 ) assessment of parameter variation:

1) Identification of relevant EOC Parameters: Within the CHOP method framework, EOCs are defined as boundary conditions that may influence, but are hardly influenced by, operation decisions on plant level, and are therefore regarded as fixed parameters. Any parameter fitting these criteria must be included as an EOC parameter.

2) Parameter variation assessment: For all identified EOC parameters, the maximum, minimum and mean parameter values over the selected period must be identified based on the reference 
datasets. As it is desirable to reduce the number of EOC parameters to define clustering from in order to keep computational effort low, it is recommended that clustering criteria are only defined for EOC parameters with variations higher than $\pm 10 \%$ of the period mean value. The potential error from neglecting variations in specific EOC parameters must be assessed as a part of the posteriori error analysis, see section 2.2.2.

Example: As illustrated in Figure 3, the CHP plant of interest imports fuel, air, and cooling water, while it produces district heating, power, exhaust gases and heated cooling water.

\section{1) Identification of the relevant EOC parameters}

The assumed objective of the CHP plant owner is to obtain the most profitable production. Being the sole heat producer in the district heating system, the production of a CHP plant is constrained by the heating demand. Assuming that cooling is freely available from a cold reservoir, air is freely available from the surroundings, and neglecting taxes on emissions, three relevant EOC parameters exist: Fuel price (coal), heating demand, and power price. Being a single plant located in the well-integrated West Denmark power grid, the power and coal prices can be considered unaffected by the production of the CHP plant. Assuming no demand flexibility on the consumer side, the heat demand is also unaffected by operation decisions. Hence, these three external parameters can be considered as EOC parameters in the CHOP method. This would not have been the case had the CHP plant been the main power producer in an isolated power grid, or if the CHP plant was fuelled by a local distributed biomass like straw [38], in which case the power and/or fuel prices would have been significantly influenced by plant operation decisions.

\section{2) Assessment of parameter variation}

Historical parameter datasets over the period 2010-01-01 - 2014-12-31 are considered for the three EOC parameters.

According to data on coal prices from Key World Energy Statistics 2014 provided by the International Energy Agency [39], the yearly average coal price in Denmark's neighbouring country Poland was 80.75 USD/ton over the years 2010-2013, with a maximum price of 84 USD/ton and a minimum price of 78 
USD/ton. Assuming that the coal price fluctuations in Poland are analogue to those in Denmark, the resulting variation range is $-3.4 \%$ to $+4 \%$ which is well below the recommended clustering threshold of $\pm 10 \%$. Therefore, the coal price is not considered as a varying EOC parameter for clustering in the case treated. The error of this assumption will be assessed as a part of the posteriori error analysis in Section 3.4. In the given case, the coal price is set to 15.70 Euro/MWh, which is the perceived coal price for 2012 reported by the Danish CHP owner DONG Energy [40].

Data on hourly power prices in West Denmark over the entire period has been extracted from the webpage of the Danish transmission system operator Energinet.dk. [41]. The average hourly power price was 40.08 Euro/MWh, with a maximum price of 2000.00 Euro/MWh and a minimum price of -200.00 Euro/MWh. As this variation is well above the recommended threshold of $\pm 10 \%$ of the mean, power price is included as a varying EOC parameter for clustering.

Data on hourly relative heat demand in a Danish district heating system over a year has been extracted from the energy system model STREAM [42]. It is assumed that the annual relative heat demand pattern is repeated for each of the 5 years investigated. The average hourly relative heat demand over the period was 0.55 , with a maximum of 1.00 and a minimum of 0.06 . As this gives in a variation of $-89 \%$ to $+82 \%$ which is well above the recommended threshold of $\pm 10 \%$ of the mean, relative heat demand is included as a varying EOC parameter for clustering.

\subsubsection{Clustering criteria}

Having identified the varying EOC parameters $p_{k}$, the second step of the CHOP data aggregation analysis is to define the clustering criteria for aggregating operating points. This is done by splitting the value range of

each $p_{k}$ into a number of characteristic intervals, $n_{p_{k}}$. Being empirical in essence, the following graphicbased two-step approach is suggested for breaking up a parameter value range into characteristic intervals based on the cumulative parameter curve. The process is illustrated in Figure 4 with power price as the relevant EOC parameter. 
a) Important values: Some parameter values may be of special interest, making it relevant to introduce a break at these points. For the power price example, it may be relevant to introduce a break at a power price of 0.00 Euro/MWh to make sure that negative prices are grouped together. Also, if an operating decision, e.g. turning on a piece of equipment, is dependent on a given power price, an interval break should be introduced at this price as well. It is also suggested that if significant trend changes occur in the cumulative curve, the parameter values of points separating various trends should be included as important values.

b) Even division: If the already set break-points are far from each other in terms of both parameter value and duration, it is suggested that additional interval breaks are introduced to minimize the span. The break-points should be located so that the parameter value range is constant for each of the intervals.

It is essential that all feasible parameter values are covered within the characteristic parameter intervals. It may be necessary to define the first and last of the characteristic intervals as open. The necessary number of intervals for each parameter depends on the parameter value volatility, the significance of the parameter and the data available. In Figure 4, six intervals were defined in the visual power price example, while it may be sufficient to define just two or three intervals for less volatile parameters. In contrast, more intervals may be defined for the power price in case it has significant impact on the optimization model. It should be noticed that if only one characteristic interval is defined for a parameter, it will be included as a constant in the final CHOP-reduced dataset.

Example: The cumulative curve for power prices, also known as the power price duration curve, is obtained by sorting the data points according to the value of the power price value. The cumulative curve illustrates the aggregated duration of power prices over the period, and is shown in Figure 5.

Using the suggested two-step approach for breaking up the cumulative curve for power prices, the following break points are obtained:

a) Important values: $0.00,25.00,65.00$ [Euro/MWh] 
b) Even division: $\quad 35.00,45.00,55.00$ [Euro/MWh]

271 This leads to seven characteristic intervals for the power price, which are summarized in Table 1.

272 The cumulative curve for the relative heat demand, which illustrates the aggregated duration of relative 273 heat loads over the period, is shown in Figure 6.

274 Using the suggested two-step approach for breaking up the cumulative curve for relative heat demand, the 275 following break points are obtained:

\subsubsection{Cluster procedure}

The final part of the data aggregation analysis is the cluster procedure, which involves the definition of

CHOP groups and clustering and aggregation of data points in the CHOP groups.

By definition, any combination of characteristic parameter intervals is a potential CHOP group. Hence, the number of potential CHOP groups in a dataset, $N_{C H O P, p o t}$, is determined by the number of characteristic parameter intervals $n_{p_{k}}$ defined for each of the varying EOC parameters $p_{k}$ :

$$
N_{C H O P, p o t}=\prod_{p_{k}} n_{p_{k}}
$$

To maintain an overview, it is suggested that the potential CHOP groups are indexed using the following key: 

parameter values. Each $\mathrm{CHOP}$ group $G_{l}$ becomes an operating point in the final dataset characterised by a duration $t_{l}$ (the sum of durations of the aggregated data points), and a number of operating condition parameters $\overline{p_{l}}$ (the weighted average parameter values of the aggregated data points).

$$
\begin{aligned}
& G\left(i_{p_{1}}, i_{p_{2}}, \ldots, i_{p_{k}}\right)=G_{l}=\left\{t_{l}, \overline{p_{l}}\right\} \\
& t_{l}=\sum_{o_{j} \in G_{l}} t_{j} \\
& \overline{p_{l}}=\frac{\sum o_{j} \in G_{l} \overline{p_{j}} \cdot t_{j}}{t_{l}}
\end{aligned}
$$

It should be noted that the vector $\overline{p_{l}}$ includes all EOC parameters, but it may also include other external parameters that are unaffected by the plant operation. It is evident that the duration $t_{j}$ represents the weight given to a given operating point $O_{j}$ in the CHOP dataset. In case the time-value of money is considered in the optimization model, $t_{j}$ can be represented in the form of present value factor $t_{P V, j}$ as well.

If no data points belong to a potential CHOP group, the group is excluded from the final CHOP dataset. Hence, the final number of CHOP groups is lower than or equal to the number of potential CHOP groups:

$$
N_{C H O P} \leq N_{C H O P, p o t}=\prod_{p_{k}} n_{p_{k}}
$$

The defined CHOP groups $G_{l}$ replace the initial dataset of operating points in an optimization model, thereby reducing the number of periods to be considered.

Example: Three EOC parameters are considered: Relative heat demand $p_{1}$, power price $p_{2}$, and coal price $p_{3}$. The number of characteristic parameter intervals are $n_{p_{1}}=7, n_{p_{2}}=7$, and $n_{p_{3}}=1$. Hence, the number of potential CHOP groups $N_{C H O P, p o t}$ is

$$
N_{C H O P, p o t}=\prod_{p_{k}} n_{p_{k}}=49
$$

Based on the reference dataset, a simple algorithm written in Excel was applied for sorting reference data points into CHOP groups. Using equations (4)-(6), the algorithm further calculated durations and parameter values for the identified CHOP groups. The processing of the entire dataset took approximately 30 seconds 
using a laptop with an Intel ${ }^{\circledR}$ Core $^{\mathrm{TM}}$ i7-3720QM CPU with $2.60 \mathrm{GHz}$ and $8 \mathrm{~GB}$ RAM. The calculated values are summarized in Table 3.

The number of CHOP groups is found to be

$$
N_{\text {CHOP }}=46<N_{C H O P, p o t}
$$
as no data points belongs to the potential CHOP groups $G(1,1), G(1,7)$ and $G(7,1)$. An illustration of the sorting of data points into CHOP groups and the resulting CHOP groups is presented in Figure 7.

\subsection{Error analysis}

\subsubsection{A priori}

Having conducted the data aggregation analysis, it is possible a priori to calculate the standard deviation $\sigma_{p_{k, l}}$ for each parameter $p_{k}$ in a CHOP group $G_{l}$.

$$
\sigma_{p_{k, l}}=\sqrt{\frac{1}{t_{l}} \sum_{j}\left(t_{j}\left(p_{k, j}-p_{k, l}\right)^{2}\right)}
$$

with $t_{j}$ being the duration of an operating point $O_{j} \in G_{l}$ and $t_{l}$ being the summarized duration of $G_{l}$. The standard deviation may give an impression of the scatter of the merged operating points within each $\mathrm{CHOP}$ group and thereby estimate the accuracy error of aggregating numbers in the defined CHOP groups. If the standard deviation of a parameter is significantly larger in one CHOP group than in the others, the cause of the deviation should be investigated. Significant standard deviations may indicate that additional characteristic intervals have to be defined in the CHOP data aggregation analysis.

Example: The standard deviation is calculated for the relative heat demand and power price of the $\mathrm{CHOP}$ groups defined in Table 3. The results are presented in Table 4 and Table 5.

Concerning the standard deviation of the relative heat demand, it is seen that the largest deviations occur for the heat intervals 3 and 4, owing to the fact that these two intervals are the ones with the largest value span. The standard deviations are not found to vary significantly, and it is therefore not considered necessary to change the characteristic intervals for the relative heat demand. 
Regarding the standard deviation of the power price, significant differences are obtained for power price intervals 1 and 7. The reason is that the intervals contain extreme parameter values as they are open towards the infinite. Especially groups $G(5,1)$ and $G(4,7)$ show large standard deviations, which is also evident from Figure 7. For $G(5,1)$, the major deviation is caused by 8 hours on the December $25^{\text {th }} 2012$ when the average power price was -174.87 Euro/MWh. For $G(4,7)$, the main cause of the large deviation is 5 hours on June $7^{\text {th }} 2013$ when the average power price was 1940.82 Euro/MWh. Based on these findings, it is not deemed relevant to change the characteristic intervals a priori.

\subsubsection{A posteriori error analysis}

Having solved an optimization model using CHOP-reduced datasets, two suggestions for a posteriori analyses are presented here: A sensitivity analysis for verifying the quality of the CHOP-groups and selection of varying EOC parameters, and an error analysis for estimating errors from neglecting time chronology-dependent constraints, such as production ramp rates or thermal storages.

To verify the quality of the $\mathrm{CHOP}$-group clustering criteria, new $\mathrm{CHOP}$ datasets can be defined from the initial EOC dataset but with additional characteristic intervals for each parameter. New operation optimization runs can then be made for selected designs using the new CHOP group datasets. If results of the various runs differ significantly, it may suggest that the characteristic intervals have been defined too loosely and that a more detailed CHOP data aggregation should be conducted for the dataset. Example: An example of how to evaluate the CHOP group clustering criteria using sensitivity analysis, and to assess the expected error of including an EOC parameter as a constant, is given in Section 3.4.

Some optimization models may include constraints that require knowledge on time chronology, for reduced datasets. If an optimization model with time chronology-dependent constraints is run using CHOPreduced EOC datasets, the error of neglecting these constraints must be assessed a posteriori. This can be done by first solving the optimization model using the CHOP-reduced EOC dataset. The found optimal 
operation pattern can then be applied on the initial EOC dataset, and the resulting error of neglecting the constraint can be calculated.

Example: An example of how to assess the error of including a thermal storage in an optimization model using a CHOP-reduced EOC dataset is presented in Section 3.5.

\section{Illustrative case: Operation optimization of a Danish extraction-based}

\section{combined heat and power plant}

In this section, the advantage of applying the CHOP method is illustrated by extending the CHP-example of section 2. Here, the operation of the fictive Danish extraction-based CHP is optimized over the 5-year period 2010-01-01 - 2014-12-31. The optimization is carried out using the entire EOC dataset, the CHOPreduced dataset, a yearly averaged dataset, a monthly averaged dataset, and a seasonal peak/off-peak averaged dataset. The results obtained are compared with respect to problem size and accuracy.

\subsection{Optimization model}

A linearized model of the existing Danish extraction-based CHP plant Avedøreværket 1 (AVV1) is developed to represent the fictive Danish CHP plant treated in the example. AVV1 was commissioned in 1990 and has a net power production of $250 \mathrm{MW}$ in condensation mode and $212 \mathrm{MW}$ in full back pressure mode with a district heating production of $330 \mathrm{MJ} / \mathrm{s}$ (drive temperature/return temperature $100^{\circ} \mathrm{C} / 50^{\circ} \mathrm{C}$ ) [43]. Part-load operation in the CHP unit is governed by sliding-pressure control [44]. The minimum load $\lambda_{\min }$ considered of $A V V 1$ is $\lambda_{\text {min }}=0.4$.

A thermodynamic model of AVV1 was previously developed by Elmegaard and Houbak [43] using the energy system simulator Dynamic Network Analysis [45]. The model was validated by Lythcke-Jørgensen et al. [25], who found that the model-predicted electrical efficiency in condensation mode was $2 \%-8 \%$ lower than that reported by the plant owner, but that the model in general was accurate with respect to electrical and first-law energy efficiency. The linearized model developed here is based on the model by Elmegaard and Houbak [43]. 
The linearized model is based on two assumptions: The power-to-heat production ratio $C_{v}$ is constant, and the fuel-consumption is a linear function of the load. Four central operating points in the reference model $\{A, B, C, D\}$ are used for developing the linearized model: $A$ is operation in full-load condensation-mode, $B$ is operation in minimum-load condensation-mode, $C$ is operation in full-load back-pressure-mode, and $D$ is operation in minimum-load back-pressure-mode.

In the linear model, the linearized operating points $A^{*}$ and $C^{*}$ are set equal to the reference points $A$ and $C$, while heat production in the linearized points $B^{*}$ and $D^{*}$ is set equal to the heat production of reference points $B$ and $D$.

$$
A^{*}=A, C^{*}=C, Q_{B}^{*}=Q_{B}, Q_{D}^{*}=Q_{D}
$$

The linearized power-to-heat ratio $C_{v}^{*}$ is defined as the average of the overall heat-to-power ratios at maximum load, $C_{v, \lambda_{\max }}$ and minimum load $C_{v, \lambda_{\min }}$ :

$$
\begin{aligned}
& C_{v, \lambda_{\text {max }}}=\frac{Q_{B}}{P_{A}-P_{B}} \\
& C_{v, \lambda_{\text {min }}}=\frac{Q_{D}}{P_{C}-P_{D}} \\
& C_{v}^{*}=\frac{C_{v, \lambda_{\text {max }}+C_{v, \lambda_{\text {min }}}}}{2}=9.406
\end{aligned}
$$

The power production in the linearized points $B^{*}$ and $D^{*}$ are found using equations (11) and (14). Data on the four reference points $\{A, B, C, D\}$ and the corresponding linearized points $\left\{A^{*}, B^{*}, C^{*}, D^{*}\right\}$ are presented in Table 6.

For any heat production $Q$, the maximum power production in the linearized model $P_{\max }^{*}$, which corresponds to a power production at a load $\lambda=1.0$, is

$$
P_{\text {max }}^{*}=P_{A}^{*}-\frac{Q}{C_{v}^{*}}
$$

Two constraints exist on the minimum power production in the linearized model, $P_{\min 1}^{*}$ and $P_{\min 2}^{*} \cdot P_{\min 1}^{*}$ is the minimum feasible power production as a consequence of the minimum load constraint $\lambda_{\min }=0.4$, while $P_{\min 2}^{*}$ is the minimum feasible power production as a consequence of the back-pressure operationmode constraint $\alpha_{\max }=1.0$. Both of these constraints must be satisfied. 


$$
P_{\min 1}^{*}=P_{C}^{*}-\frac{Q}{C_{v}^{*}}
$$

$$
P_{\min 2}=P_{D}^{*}+\left(Q-Q_{D}^{*}\right) \frac{P_{B}^{*}-P_{D}^{*}}{Q_{B}^{*}-Q_{D}^{*}}
$$

The feasible power-heat operation area of the linearized model is defined by the constraints (15)-(17). The power-heat operation area of the reference model, the linearized model, and the four reference operating points $\{A, B, C, D\}$ are shown in Figure 8 .

Evaluating the accuracy of the linear approximated equations (15)-(17), it is found that the accuracy on the power constraints is within $-1.45 \%$ to $2.69 \%$. The largest negative deviation occurs for the maximum power production at $Q=194.5 \mathrm{MJ} / \mathrm{s}$, and the largest positive deviation occurs for the minimum power production at $Q=118.6 \mathrm{MJ} / \mathrm{s}$.

In the linearized model, the load can be calculated as a function of the heat and power production:

$$
\lambda(P, Q)=\lambda_{\min }+\left(1-\lambda_{\min }\right) \frac{\left(P+\frac{Q}{C_{v}^{*}}\right)-P_{C}^{*}}{P_{A}^{*}-P_{C}^{*}}
$$

The linearized fuel consumption $F^{*}(\lambda)$ in $\mathrm{MJ} / \mathrm{s}$ as a function of the load is found using the first-order trendline function in Microsoft Excel on data for fuel consumption at various loads in the AVV1 model.

$$
F^{*}(\lambda)=F^{*}(P, Q)=499.64 \cdot \lambda(P, Q)+102.179
$$

427 A coefficient of determination of $R^{2}=0.9998$ was obtained for this trendline function.

428 The operation of the fictive Danish CHP plant is to be optimized with the aim of minimizing the costs of producing heat to the district heating network over the period 2010-01-01 - 2014-12-31. The variables of the optimization model are the power production $P_{j}$ and heat production $Q_{j}$ in each period $j$. As discussed in Section 2.1., the CHP production is constrained by the heating demand which has to be met at all times. To simplify matters, thermal energy storage is neglected, hence $Q_{j}$ is constrained by

$$
Q_{j}=Q_{j, r e f} \forall j
$$

The power production $P_{j}$ is constrained by equations (15)-(17). Full hour-wise operation flexibility is 
Assuming that operation and maintenance costs are constant and therefore indifferent to the choice of $\left(Q_{j}, P_{j}\right)$, that air is free and cooling is freely available from a cold reservoir, and neglecting taxes on emissions, the objective function to be minimized can be defined as

$$
C_{\text {heat }}\left(Q_{j}, P_{j}\right)=\sum_{j}\left[F^{*}\left(P_{j}, Q_{j}\right) \cdot c_{f u e l, j}-P_{j} \cdot c_{p, j}\right]
$$

Here, $C_{\text {heat }}\left(Q_{j}, P_{j}\right)$ is the variable cost of the heat production, $c_{f u e l, j}$ is the cost of fuel, and $c_{p, j}$ is the power price in each operating point $j$.

Given equations (15)-(21), the optimization problem can be written in condensed form as

$$
\left\{\begin{array}{l}
\min _{Q, P}\left[C_{\text {heat }}\left(Q_{j}, P_{j}\right)\right] \\
\quad \text { subject to constraints: } \\
\text { equations }(15),(16),(17),(20) \\
\quad \text { with variables: } \\
P_{j}, Q_{j} \in \mathbb{R}^{+}
\end{array}\right.
$$

\subsection{External operating conditions datasets}

Five different EOC datasets are used for solving optimization problem (22): The full EOC dataset, which is obtained by combining data on hourly power prices in the West Denmark power grid [41] with data on hourly relative heat demand for Denmark [42], as discussed in Section 2.1.2; the CHOP-reduced EOC dataset $D_{C H O P}$, which is presented in Table 3; the annually averaged EOC dataset $D_{A A}$, in which the EOC parameter values are averaged over each of the five years; the monthly averaged EOC dataset $D_{M A}$, in which the EOC parameter values are averaged over each of the 60 months in the period; and, finally, the seasonal peak/off-peak averaged EOC dataset $D_{S P}$, which is inspired by the approach taken by Chen et al. [2] for representing EOC parameters. Here, EOC parameter values are averaged over the peak period, 7 a.m.-11 p.m., and off-peak period, 11 p.m.-7 a.m., for each of the four seasons each year. Datasets $D_{A A}$, $D_{M A}$, and $D_{S P}$ are presented in the Appendix. A scatter diagram illustrating the reference EOC dataset and the reduced datasets is presented in Figure 9.

Figure 9 illustrates how the parameter value diversity of the reference dataset is sustained in the various reduced datasets. It is seen that the annual average EOC dataset yields five points, all located in the centre of Figure 9, that are almost identical with respect to relative heat demand and power price. The monthly 
averaged and seasonal peak/off-peak averaged EOC datasets are seen to be more distributed, but the resulting operating points are still far from the boarders of the dense cloud of reference operating points. Opposed to this, both the CHOP and the CHOP-revised EOC datasets are seen to be significantly more distributed in the figure, suggesting that a larger degree of the diversity in the reference dataset is sustained in these reduced datasets.

\subsection{Results and comparison}

465 The optimization problem (21) is solved using the open-source mixed-integer program solver CBC (COIN Branch and Cut) [46] in OpenSolver 2.6.1 [47] for Microsoft Excel. The optimization results obtained using each of the five EOC datasets are summarized in Table 7.

Firstly, it is evident that by optimizing the operation of the CHP unit using the full dataset it is possible to optimization problem (21) under the given conditions and assumptions, and the results obtained using the full dataset are used as reference values for further comparison. Among the reduced EOC datasets, the result obtained using $D_{C H O P}$ gets closest to the reference value with a deviation of 0.38 MEuro in total variable heat cost. Compared to this, the deviation is 8.15 MEuro when using $D_{A A}, 7.64$ MEuro using $D_{M A}$, and 5.58 MEuro using $D_{S P}$. In terms of computation time, the number of calculations to be performed is 5 when using $D_{A A}, 60$ when using $D_{M A}, 40$ when using $D_{S P}$, and 46 when using $D_{C H O P}$. Hence, $D_{C H O P}$ obtains the most accurate economic result of the reduced datasets for the case, 478 and $D_{S P}$. This demonstrates the relevance of the CHOP method for reducing datasets on external operating conditions.

For the results obtained using $D_{A A}, D_{M A}$ and $D_{S P}$, it is seen that the total power production and fuel consumption are larger than the reference values. This is caused by the fact that the operation optimization only considers the average power prices of the periods. Hence, if the average power price over a given period is economically attractive for power production at the plant, power production is maximized over 
the entire period even though the power price may not be attractive in all hours. This phenomenon results in an increased power production, but also in increased fuel costs that exceed the increased income from power sales and yielding a higher $C_{\text {heat }}$ for the three solutions compared to the reference solution. The opposite trend, where power production is minimized for entire periods containing data points with advantageous power prices, also occurs when using $D_{A A}, D_{M A}$ and $D_{S P}$, but the first trend is found to be dominant in the present case.

In contrast, the result obtained using the $D_{C H O P}$ dataset underestimates the power production in the case investigated, and also shows reduced income from power sales. At the same time an almost equal reduction in fuel costs occurs, resulting in the relatively low deviation in the heat price compared to the reference result. The explanation is that in the CHOP method, the data points merged in CHOP groups have similar parameter values. Hence, averaged parameter values are close to the parameter values of the data points. If the power is minimized over a data point where it would be maximized in the reference case, or vice versa, the economic difference is small. Thus, when using the $D_{C H O P}$ dataset, the economic result is very close to that of the reference optimization.

Comparing the accuracy of results, it is seen that the estimated fuel consumption and power production are overestimated by $2.5 \%$ and $3.4 \%$ using $D_{A A}$, by $4.4 \%$ and $5.7 \%$ using $D_{M A}$, by $2.2 \%$ and $2.8 \%$ using $D_{S P}$, while they are underestimated by $3.1 \%$ and $4.1 \%$ using $D_{C H O P}$. This indicates that the optimal operation pattern predicted using $D_{C H O P}$ is different from the reference optimum for a significant amount of operating points for the given case, suggesting that the CHOP clustering criteria could be improved. This had not been obvious if the reference solution had not been known, or if only the economic objective had been considered. Therefore, it is suggested that sensitivity analysis is applied a posteriori for evaluating the quality of the applied clustering criteria, and thereby assessing the accuracy of the results.

\subsection{Sensitivity analysis}

A posteriori, sensitivity analyses are conducted to evaluate the quality of the entity selection and the applied clustering criteria. 
First, the impact of not including coal price as a varying EOC parameter in the CHOP analysis is assessed. As described in Section 2.1.1., the data suggested that the coal price varied within the range $-3.4 \%$ to $+4 \%$ of the average price over the period. It is here assessed how such variations would affect the optimized operating pattern when using the CHOP dataset.

In the optimization model, the heat production is constrained and therefore unaffected by the coal price. However, power production is flexible and depends on power prices and coal prices. The impact on power production and fuel consumption from varying the coal price within the range $\pm 5 \%$ over the entire period is shown in Figure 10. It is seen that if the coal price is reduced by $5 \%$, the power production is increased by $1.2 \%$ and the fuel consumption by $0.9 \%$. Apart from this, the power production and fuel consumption are hardly affected by variations in the coal price over the set range. It is therefore considered acceptable to use the average coal price value in the CHOP dataset. Next, the applied clustering criteria are assessed. Here, the number of characteristic intervals defined for the relative heat demand and power price is varied and new $\mathrm{CHOP}$ datasets are obtained. The optimization model is then run using each of the new CHOP datasets to evaluate the impact on the results of changing the clustering criteria.

Three sensitivity analyses are considered: Heat interval sensitivity, where the number of intervals defined for the relative heat demand is changed; power interval sensitivity, where the number of intervals defined for the power price is changed; and combined heat and power interval sensitivity, where the number of intervals defined for both the relative heat demand and the power price are changed simultaneously. The interval break points defined for the sensitivity analyses are given in Table 8. with respect to income result, fuel cost, power production and power sales. The outcomes are presented in Figures 11-14.

Figure 11 shows the variations in total variable heat cost from the different sensitivity analyses. It is seen that reducing the number of power intervals with the suggested break-points significantly increases the 
total variable heat cost, while increasing the number of intervals leads to slightly better results. A stable level is reached when increasing the number of power price intervals to $8-10$ with the set break points. This suggests that the number of characteristic intervals for the power price should be increased in order to obtain a robust solution. Opposed to this, the result is almost unaffected by the number of relative heat demand intervals defined, suggesting that the initial resolution of 7 characteristic heat demand intervals is sufficient. Both findings are supported by the combined heat and power intervals sensitivity analysis, the trend of which is almost identical to that of the power interval sensitivity.

Furthermore, the findings above are supported by the analogue results obtained when comparing the sensitivity analysis results with respect to fuel costs (Figure 12), power production (Figure 13), and power sales (Figure 14). Again, it is found that the results are somewhat unaffected by minor changes in the number of relative heat demand characteristic intervals, while the results obtained become stable when the number of power price intervals is increased to 8 or more using the suggested interval break-points. The sensitivity analysis suggests that the CHOP dataset should be reconfigured by changing the number of characteristic power price intervals to 8 using the interval break-points presented in Table 8. The revised CHOP dataset is presented in Table 9, while results obtained using the revised CHOP dataset are presented in Table 10. The results show that the $C_{\text {heat }}$ obtained is practically identical to that found using the reference data when applying the revised $\mathrm{CHOP}$ dataset, while the power production and fuel consumption are underestimated by less than $1 \%$, suggesting that the revised clustering criteria is more accurate than the initial one. In terms of reduction in relative computation time, the revised CHOP dataset requires 53 calculations, a number which is comparable to the number of calculations required when using $D_{M A}$ and $D_{S P}$ as well.

\subsection{Optimization with thermal energy storage}

As discussed by Rolfsman [48], the income from power sales in CHP plants may be increased by installing thermal energy storages that allows for production shifting in periods with high power prices. Similar results were reported by Martinéz-Lear et al. [49] for combined heating, cooling and power plants for 
buildings. Hence, optimization models of multi-generation plants dealing with heating or cooling production should preferably include an option for thermal storage. In this section, the optimization model (22) is rewritten to include short-term heat storage, and the error made from solving the problem using the revised CHOP dataset (Table 9) is assessed.

In the case of the fictive Danish CHP plant, it is assumed that a thermal energy storage capable of storing 24 hours of peak heat production is available on site.

$$
Q_{\text {storage } \max }=24 \cdot 332.91 M W h=7990 M W h
$$

Heat losses are neglected in the thermal energy storage model. The thermal energy storage content

$Q_{\text {storage, } j}$ is calculated as

$$
Q_{\text {storage }, j}=Q_{\text {storage }, j-1}+\left(Q_{j}-Q_{j, r e f}\right), Q_{\text {storage }, 0}=0
$$

In the rewritten optimization problem, the constraint (19) is slacked and replaced by a new constraint stating that the total heat production over the entire period must equal the total heat consumption

$$
\sum_{j} Q_{j}=\sum_{j} Q_{j, r e f}
$$

Furthermore, two constraints are introduced representing the physical constraints of the thermal energy storage:

$$
\begin{aligned}
& Q_{\text {storage }, j} \leq Q_{\text {storage,max }} \\
& Q_{\text {storage }, j} \geq 0
\end{aligned}
$$

Given equations (15)-(19) and (23)-(27), the optimization problem with thermal energy storage can be written in condensed form as

$$
\left\{\begin{array}{l}
\min _{Q, P}\left[C_{\text {heat }}\left(Q_{j}, P_{j}\right)\right] \\
\quad \text { subject to constraints: } \\
\text { equations }(15),(16),(17),(25),(26),(27) \\
\quad \text { with variables: } \\
P_{j}, Q_{j} \in \mathbb{R}^{+}
\end{array}\right.
$$

As constraints (26) and (27) require knowledge of the time chronology of the data points, the optimization problem (28) cannot be solved using the CHOP-reduced dataset. Therefore, constraints (26) and (27) were 
slacked, and the resulting error was evaluated a posteriori. Results obtained from solving the problem (28) using the full EOC dataset and the revised CHOP dataset are presented in Table 11. obtained, as opposed to the solution where no heat storage was considered and a total variable heat cost of 0.38 MEuro was obtained. The negative costs means that power sales exceed the total fuel costs in optimal operation for the CHP plant. The result suggests that short-term thermal energy storage is an economic advantage in CHP production, supporting the outcomes presented by Rolfsman [48] and Martinéz-Lear et al. [49]. It is further seen that the power production is slightly reduced while incomes from power sales are increased when comparing to the situation without heat storage. This is owing to the fact that heat storage allows for a more flexible production.

Solving problem (28) with the revised CHOP dataset gives a total variable heat cost of -8.06 MEuro. It is seen that the power production, power sales, and fuel consumption are all reduced when compared to the solution obtained using the full EOC dataset. The economic result is slightly improved when compared to the result obtained using the full EOC dataset. However, the results cannot be directly compared without assessing the error that slacking of constraints (26) and (27) imposes on the CHOP solution. By applying the optimal operation pattern predicted by the CHOP solution on the chronological EOC dataset, it is possible to evaluate the contents of the thermal energy storage over the 5-year period investigated. A plot of the thermal energy storage contents over the 5-year period for the optimal solutions to problem (28) obtained using the full EOC dataset and the revised CHOP dataset is presented in Figure 15. It is seen that the CHOP solution significantly violates the physical constraints of the thermal energy storage in the model over the 5-year period. The explanation is quite simple: When slacking constraints (26) and (27), the only constraint on the heat production is that heat production and consumption must be balanced over the entire period. As the power prices on average were higher in the first two years of the period (consult Table 12 in the Appendix), power production is maximized at the cost of heat production in 2010 and 2011, while excess heat is produced the following years when power prices are lower. It can also be 
deducted from the graph that additional heat is produced in the summer periods when demand is low, and then stored for use in the winter when heat demand is high. Though highly intuitive, this solution is infeasible in reality due to thermal energy storage constraints. The results illustrates that the CHOP method may not be suitable for data reduction in models where short-term thermal energy storage is considered.

\section{Discussion and perspective}

As the optimization of FMG concepts is complex and involves such challenges as synthesising and dimensioning of processes, process integration, and operation optimization, it is desirable to reduce external operating condition (EOC) datasets to be used in multi-period optimization models in order to make the models solvable. The CHOP method presented in this paper is a simple method for reducing EOC datasets by clustering data points in groups. The main advantages of the CHOP method include the significant reduction in the size of input data to multi-period optimization problems and the consequent reduction in computation costs, the simple and straight-forward use, and the fact that short-term relations and variations between various operating conditions are sustained in CHOP-reduced dataset.

For the simple case study presented in this paper, which treated the operation optimization of a fictive Danish CHP plant, it was found that the solution obtained using the revised CHOP-reduced EOC dataset had a much higher accuracy in terms of economic result and estimations of power production and fuel consumption than the solutions obtained using chronology-averaged EOC datasets. Furthermore, it was found that the revised CHOP dataset reduced the relative amount of computations by approximately a factor 827 , which is comparable to the reductions of approximately a factor 730 when using monthly averaged dataset and approximately a factor 1096 when using the peak/off-peak averaged dataset. For the simple case, the advantage of the reduction in computation costs was not evident as the linear optimization problem could be solved within a minute using the full dataset. However, if more advanced optimization models needed be evaluated, e.g. non-linear operation optimization models, and if these further needed be solved for a large number of different designs for each operating point as in the design optimization of complex FMGs, reductions in computation costs is needed. Hence, the combination of high 
accuracy and significant reduction in computation time support the proposition that the CHOP method is relevant for reducing EOC datasets to be used in optimization models of FMGs, and that the method is to be preferred over any of the three averaging methods mentioned in this paper. The advantage of sustaining information on short-term parameter relations will assumedly be even more significant in more complex optimization models that consider multiple processes. For instance, if a process was considered for integration in the case study CHP plant which would only be economic advantageous to run when power prices are below 25.00 Euro/MWh, it would never be operated if annual or monthly averaged datasets were applied in the optimization model, while it would be run for 2192 hours over the five year period if the peak/off-peak averaged dataset was used, and for 4550 hours, or more than $10 \%$ of the time, if the CHOP-reduced dataset or the reference dataset were applied. Sustained data diversity in CHOP-reduced datasets thus allows for more accurate solutions. The fact that a large part of the initial dataset parameter diversity is sustained in the CHOP-reduced dataset is also evident from Figure 9, which illustrates how the parameter diversity in defined CHOP groups is significantly larger than for any of the three averaged datasets. Furthermore, for equipment with performance that is a non-linear function of an EOC parameter, e.g. the power production of a wind turbine as a function of the wind speed, the use of CHOP-reduced datasets rather than chronological-averaged datasets will assumedly yield more accurate results.

Another advantage of the CHOP method is the fact that larger datasets do not necessarily yield larger reduced datasets. In the case study, hourly heat demand and power price data were considered for a 5year period. The initial 43,824 data points were reduced to 60 data points using the monthly averaging method, 40 data points using the seasonal peak/off-peak averaging method, and 53 using the CHOP method. If the period considered was extended to a 30 -year period, the number of data points would be multiplied by six for each of the chronological-averaged methods, while it is likely that the number of 654 CHOP-groups would not need to be changed. Instead, the weight given to each of the CHOP groups defined would increase as the additional data points are sorted into the groups. However, it is likely that the 
increase in weight will not be the same for all CHOP groups due to the development of the energy system.

657 If the time-value of money needs to be considered, the time weight given to each sorted data point can be replaced by a present value weight factor, as discussed in section 2.1.3., allowing for net present value calculations in design optimization models.

Error analysis is central in the CHOP method as it provides the feedback required to optimize the data aggregation strategy. In the present work, a number of approaches for conducting the error analysis were suggested. However, it must be emphasized that other methods may be applied as long as they do not counteract the initial ambition of reducing overall computation time. One example of a method that may be useful for error analysis in the CHOP method is the global sensitivity analysis Morris Screening [50], which could be applied a posteriori for assessing the quality of the defined characteristic interval breaks by estimating the aggregated impact of varying EOC parameters within the defined intervals, or to evaluate if a non-clustering EOC parameter ought to be included in the clustering analysis.

668 Two significant draw-backs exist for the CHOP method. Firstly, the number of CHOP groups defined is 669 combinatorial as a function of the relevant EOC parameters defined for a given problem. In the case study, three EOC parameters were considered, of which one was excluded from the clustering analysis, and seven 671 and eight characteristic intervals were defined for the other two, resulting in 56 potential CHOP groups according to equation (2). However, if two additional EOC parameters were considered for clustering with four characteristic intervals each, the number of potential CHOP groups would increase to 896 . Even 674 though the final number of CHOP groups may be lower according to equation (7), the combinatorial issue 675 represents a significant challenge when applying the CHOP method on datasets with multiple EOC 676 parameters. This also explains why it is relevant to seek to exclude less volatile parameters from the CHOP 677 data aggregation in the entity selection. One way of circumventing the combinatorial issue is to set up 678 relations for deriving various parameters from a few EOC parameters. For example, it may be possible to 679 derive formulas for heating and cooling demands as a function of the outdoor temperature [51] or the cost 680 of various fuels as a function of the expected oil price [2]. If such relations are introduced, the uncertainty 
of the applied relations should be included in the sensitivity and error analyses conducted for results obtained.

Secondly, the CHOP method does not permit consideration of dynamics and time chronology directly, which is also the case for yearly- and monthly-averaged datasets. This implies that ramp constraints on operation cannot be considered, potentially resulting in infeasible operation patterns as discussed by Rong and Lahdelma [52], and that thermal energy storages cannot be directly included, as discussed in section 3.5. Also, scheduling of maintenance shut-downs cannot be considered when using CHOP-reduced datasets, and neither can investment planning if the entire reference dataset is reduced to a single CHOP-reduced dataset. The latter can be solved by setting a time-span for investment planning, e.g. 5 years, and then derive a CHOP-reduced dataset for every 5-year period. However, this would increase the size of the dataset significantly, counteracting one of the initial advantages of the CHOP-method.

To overcome the challenges of including thermal energy storage and ramp constraints, it is suggested that CHOP-reduced datasets, rather than yearly or monthly reduced datasets, are applied in a first-step design optimization run, and that a detailed operation optimization is carried out in a sequential step for the most promising designs, similar to the method presented by Rubio-Maya et al. [22] and Uche et al. [23].

\section{Conclusion}

This study presents a novel and simple method, the Characteristic Operating Pattern (CHOP) method, for reducing external operating condition (EOC) datasets in optimization models. The method has been tailored for optimization models of flexible multi-generation plants (FMGs), but may be suitable for any optimization model that involves a flexible facility operating on multiple markets.

In a case study, an operation optimization model of a Danish extraction-based combined heat and power plant is solved using the full EOC dataset, a CHOP-reduced EOC dataset, a yearly-averaged EOC dataset, a monthly-averaged EOC dataset, and a seasonal peak/off-peak EOC dataset. The results indicate that the CHOP-reduced dataset yields by far the most accurate solution among all the reduced EOC datasets, while achieving a reduction in the problem size similar to those achieved of using monthly-averaged and seasonal 
peak/off-peak-averaged datasets. It is found that CHOP-reduced datasets are not suited for models that consider short-term thermal energy storage as time chronology is not considered.

The outcomes of the paper suggest that the CHOP method is better suited for reducing EOC datasets in optimization models of FMGs than any of the three chronology-averaged methods used for comparison in this paper. If short-term thermal energy storage or ramp constraints are considered, it is suggested that the CHOP method is applied in a first-step design optimization method, and that detailed operation optimization, including dynamic constraints, is carried out in a sequential step for the most promising designs. The latter will be a topic for future research by our group.

\section{Acknowledgements}

The authors would like to acknowledge DONG Energy for their financial support of the research.

\section{References}

[1] H. Lund, Renewable energy systems: the choice and modelling of $100 \%$ renewable solutions, Burlington, USA: Elsevier, 2010.

[2] Y. Chen, T. A. Adams II and P. I. Barton, "Optimal Design and Operation of Flexible Energy Polygeneration Systems," Industrial \& Engineering Chemistry Research, no. 50, pp. 4553-4566, 2011.

[3] A. Coronas, S. S. Murthy and J. C. Bruno, "Editorial for the special issue of applied thermal engineering on polygeneration," Applied Thermal Energy, no. 50, pp. 1397-1398, 2013.

[4] M. Gassner and F. Maréchal, "Increasing Efficiency of Fuel Ethanol Production from Lignocellulosic Biomass by Process Integration," Energy Fuels, no. 27, pp. 2107-2115, 2013.

[5] O. Edenhofer, R. Pichs-Madruga and Y. Sokona, "Renewable Energy Sources and Climate Change Mitigation," Intergovernmental Panel on Climate Change and Cambridge University Press, New York, USA, 2012.

[6] L. Daianova, E. Dotzauer, E. Thorin and J. Yan, "Evaluation of a regional bioenergy system with local production of biofuel for transportation, integrated with a CHP plant," Applied Energy, no. 92, pp. 739749, 2011.

[7] D. D. Ilic, E. Dotzauer and L. Trygg, "District heating and ethanol production through polygeneration in 
Stockholm," Applied Energy, no. 91, pp. 214-221, 2011.

[8] T. Kohl, M. Teles, K. Melin, T. Laukkanen, M. Järvinen, S. W. Park and R. Guidici, "Exergoeconomic assessment of CHP-integrated biomass upgrading," Applied Energy, no. 156, pp. 290-305, 2015.

[9] B. Mathiesen, H. Lund, D. Connolly, H. Wenzel, P. Østergaard, B. Möller, S. Nielsen, I. Ridjan, P. Karnøe, K. Sperling and F. Hvelplund, "Smart Energy Systems for coherent $100 \%$ renewable energy and transport solutions," Applied Energy, no. 145, pp. 139-154, 2015.

[10] B. Mathiesen, H. Lund, D. Connolly, H. Wenzel, P. Østergaard, B. Möller, S. Nielsen, I. Ridjan, P. Karnøe, K. Spelling and F. Hvelplund, "Smart Energy Systems for coherent 100\% renewable energy and transport solutions," Applied Energy, no. 145, pp. 139-154, 2015.

[11] D. Connolly, H. Lund, B. Mathiesen and M. Leahy, "A review of computer tools for analysing the integration of renewable energy in various energy systems," Applied Energy, no. 87, pp. 1059-1082, 2010.

[12] M. Hindsberger and H. F. Ravn, "Multiresolution modeling of hydro-thermal systems," in PICA: 22ND IEEE POWER ENGINEERING SOCIETY INTERNATIONAL CON FERENCE ON POWER INDUSTRY COMPUTER APPLICATIONS, Sydney, Australia, 2001.

[13] R. R. Iyer and I. E. Grossmann, "Synthesis and operational planning of utility systems for multiperiod operation," Computers \& Chemical Engineering, no. 22, pp. 979-993, 1998.

[14] P. Ahmadi, M. A. Rosen and I. Dincer, "Multi-objective exergy-based optimization of a polygeneration energy system using an evolutionary algorithm," Energy, no. 46, pp. 21-31, 2012.

[15] M. Gassner and F. Maréchal, "Thermo-economic optimisation of the polygeneration of synthetic natural gas (SNG), power and heat from lignocellulosic biomass by gasification and methanation," Energy \& Environmental Science, no. 5, pp. 5768-5789, 2012.

[16] Y. Chen, T. A. Adams II and P. I. Barton, "Optimal Design and Operation of Static Energy Polygeneration Systems," Industrial \& Engineering Chemistry Research, no. 50, pp. 5099-5113, 2010.

[17] P. Liu, D. I. Gerogiorgis and E. N. Pistikopoulus, "Modeling and optimization of polygeneration energy systems," Catalysis Today, no. 127, pp. 347-359, 2007.

[18] P. Liu, E. N. Pistikopoulus and Z. Li, "A Multi-Objective Optimization Approach to Polygeneration Energy Systems Design," Process Systems Engineering, no. 56, pp. 1218-1234, 2010.

[19] P. Liu, E. N. Pistikopoulus and Z. Li, “Environmentally Benign Process Design of Polygeneration Energy Systems," in Design for Energy and the Environment, Taylor and Francis Group, LLC, 2010, pp. 585-592.

[20] S. Fazlollahi, P. Mandel, G. Becker and F. Maréchal, “Methods for multi-objective investment and 
operating optimization of complex energy systems," Energy, no. 45, pp. 12-22, 2012.

[21] S. Fazlollahi and F. Maréchal, "Multi-objective, multi-period optimization of biomass conversion technologies using evolutionary algorithms and mixed integer linear programming (MILP)," Applied Thermal Engineering, no. 50, pp. 1504-1513, 2013.

[22] C. Rubio-Maya, J. Uche-Marcuello, A. Martinéz-Garcia and A. A. Bayod-Rújula, "Design optimization of a polygeneration plant fuelled by natural gas and renewable energy sources," Applied Energy, no. 88, pp. 449-457, 2011.

[23] C. Rubio-Maya, J. Uche and A. Martínez, "Sequential optimization of a polygeneration plant," Energy Conversion and Management, no. 52, pp. 2861-2869, 2011.

[24] A. Christidis, C. Koch, L. Pottel and G. Tsatsaronis, "The contribution of heat storage to the profitable operation of combined heat and power plants in liberalized electricity markets," Energy, no. 41, pp. 7582, 2011.

[25] C. Lythcke-Jørgensen, F. Haglind and L. R. Clausen, "Exergy analysis of a combined heat and power plant with integrated lignocellulosic ethanol production," Energy Conversion and Management, no. 85, pp. 817-827, 2014.

[26] C. Lythcke-Jørgensen and F. Haglind, "Design optimization of a polygeneration plant producing power, heat, and lignocellulosic ethanol," Energy Conversion and Management, no. 91, pp. 353-366, 2015.

[27] C. Lythcke-Jørgensen, M. Münster, A. V. Ensinas and F. Haglind, "Design optimization of flexible biomass-processing polygeneration plants using characteristic operation periods," in World Renewable Energy Congress XIII, Kingston-upon-Thames, London, 2014.

[28] Y. Chen, T. A. Adams II and P. I. Barton, "Decomposition Strategy for the Global Optimization of Flexible Energy Polygeneration Systems," American institute of Chemical Engineers, no. 58, pp. 3080-3095, 2012.

[29] G. Mavrotas, D. Diakoulaki, K. Florios and P. Georgiou, "A mathematical programming framework for energy planning in services' sector buildings under uncertainty in load demand: The case of a hospital in Athens," Energy Policy, no. 36, pp. 2415-2429, 2008.

[30] J. Ortiga, J. Bruno and A. Coronas, "Selection of typical days for the characterisation of energy demand in cogeneration and trigeneration optimisation models for buildings," Energy Conversion and Management, no. 52, pp. 1934-1942, 2011.

[31] F. Domínguez-Moñoz, J. M. Cejudo-López, A. Carrilo-Andrés and M. Gallardo-Salazar, "Selection of typical demand days for CHP optimization," Energy and Buildings, no. 43, pp. 3036-3043, 2011.

[32] S. Fazlollahi, S. L. Bungener, P. Mandel, G. Becker and F. Maréchal, "Multi-objectives, multi-period optimization of district energy systems: I. Selection of typical operating periods," Computers and 
Chemical Engineering, no. 65, pp. 54-66, 2014.

[33] K. Hedegaard and M. Münster, "Influence of individual heat pumps on wind power integration Energy system investments and operation," Energy Conversion and Management, no. 75, pp. 673-684, 2013.

[34] S. Bungener, R. Hackl, G. V. Eetvelde, S. Harvey and F. Marechal, "Multi-period analysis of heat integration measures in industrial clusters," Energy, (in press).

[35] A. Nemet, J. J. Klemes, P. S. Varbanov and Z. Kravanja, "Methodology for maximising the use of renewables with variable availability," Energy, no. 44, pp. 29-37, 2012.

[36] DTU Management Engineering; Danish Energy Agency, 1 December 2013. [Online]. Available: http://www.ens.dk/sites/ens.dk/files/info/facts-figures/scenarios-analysesmodels/models/IntERACT/wp03_-_interact_times-dk_phase_1.pdf. [Accessed 7 July 2015].

[37] Nord Pool Spot, “Nord Pool Spot,” [Online]. Available: http://www.nordpoolspot.com/\#/nordic/table. [Accessed 4 November 2014].

[38] M. W. Jack, "Scaling laws and technology development strategies for biorefineries and bioenergy plants.," Bioresource Technology, no. 100, pp. 6324-6330, 2009.

[39] International Energy Agency, "Key World Energy STATISTICS 2014," International Energy Agency, Paris, 2014.

[40] C. Lythcke-Jørgensen, "Modelling and Optimization of a Steam Co-generation Plant with Integrated Bio-ethanol Production," Technical University of Denmark, Kgs. Lyngby, 2012.

[41] Energinet.dk, “Market data," Nord Pool Spot, [Online]. Available: energinet.dk. [Accessed 28 January 2015].

[42] http://www.streammodel.org/, "The STREAM modelling tool," Ea Energy Analyses. [Online]. [Accessed 3 April 2014].

[43] B. Elmegaard and N. Houbak, "Simulation of the Avedøreværket Unit 1 cogeneration plant with DNA," in 16th International Conference on Efficiency, Cost, Optimization, Simulation and Environmental Impact of Energy Systems, DK-2800 Kgs. Lyngby, 2003.

[44] H. Spliethoff, Power Generation from Solid Fuels, München, Germany: Springer-Verlag Berlin Heidelberg, 2010.

[45] B. Elmegaard and N. Houbak, "DNA - A General Energy System Simulation Tool," in SIMS, 2005.

[46] J. Forrest and R. Lougee-Heimer, “CBC User Guide," 2015. [Online]. Available: http://www.coin- 
or.org/Cbc/.

[47] OpenSolver, OpenSolver, 2015. [Online]. Available: opensolver.org.

[48] B. Rolfsman, "Combined heat-and-power plants and district heating in a deregulated electricity market," Applied Energy, no. 78, pp. 37-52, 2004.

[49] S. Martinéz-Lera, J. Ballester and J. Martinéz-Lera, "Analysis and sizing of thermal energy storage in combined heating, cooling and power plants for buildings," Applied Energy, no. 106, pp. 127-142, 2013.

[50] M. D. Morris, "Factorial Sampling Plans for Preliminary Computational Experiments," Technometrics, vol. 33, no. 2, pp. 161-174, 1991.

[51] S. Frederiksen and S. Werner, "Heat and cold loads," in District Heating and Cooling, Lund, Sweden, Studentlitteratur AB, 2013, pp. 67-112.

[52] A. Rong and R. Lahdelma, "An effective heuristic for combined heat-and-power production planning with power ramp constraints," Applied Energy, no. 84, pp. 307-325, 2007.

718

719

720

721

722

\section{Appendix}

This appendix presents the reduced external operating condition (EOC) datasets $D_{A A}$ (Table 12), $D_{M A}$

(Tables 13-15), and $D_{S P}$ (Tables 16-18) as explained in Section 3.2. 
Figure 1

Initial dataset

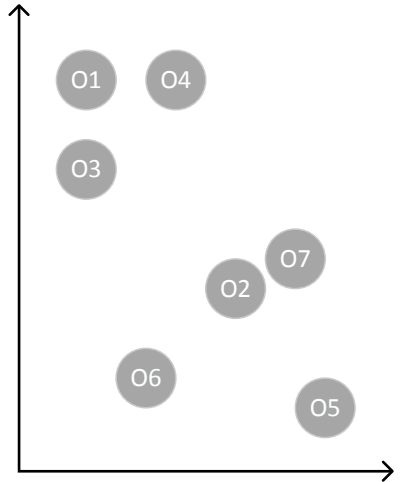

Clustering criteria

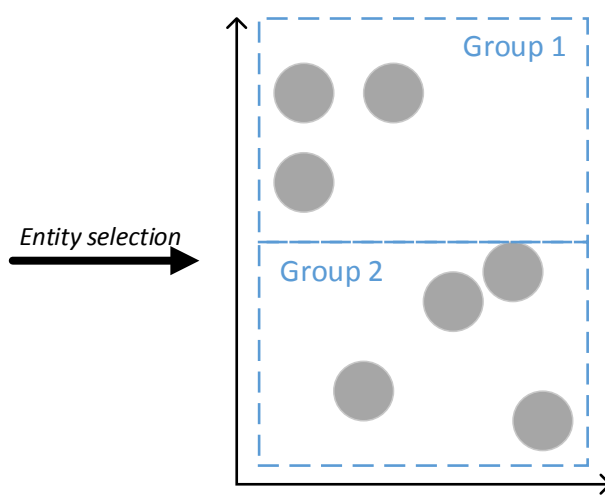

CHOP-reduced dataset

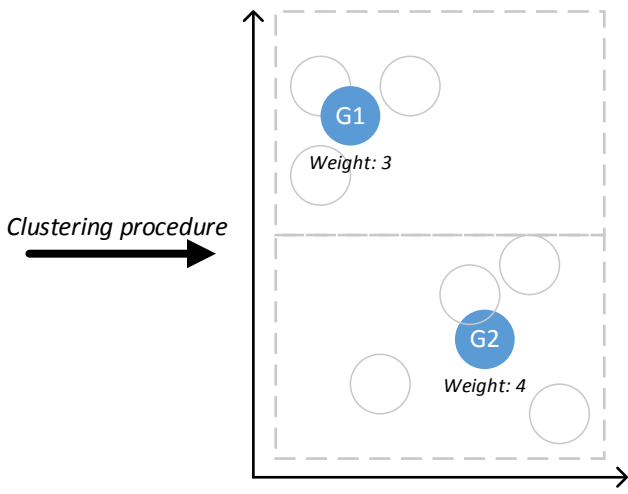


Figure 1 Caption

Figure 1 - Principal sketch of the data aggregation principle applied in the CHOP method. Operating points

$O_{j}$ are clustered and merged into $\mathrm{CHOP}$ groups $G_{j}$ with aggregated weight factors. 


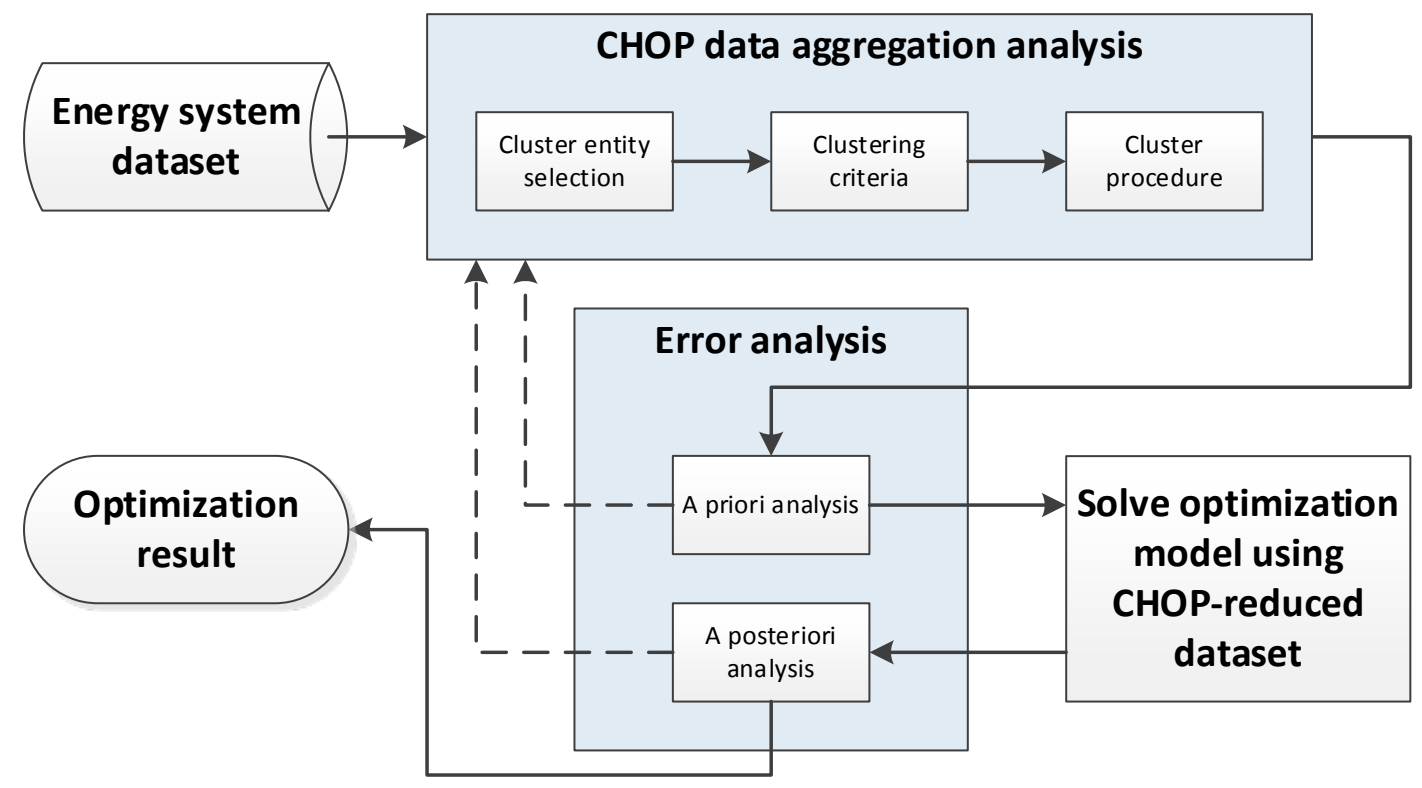


Figure 2 Caption

Figure 2 - The CHOP method procedure. 
Figure 3

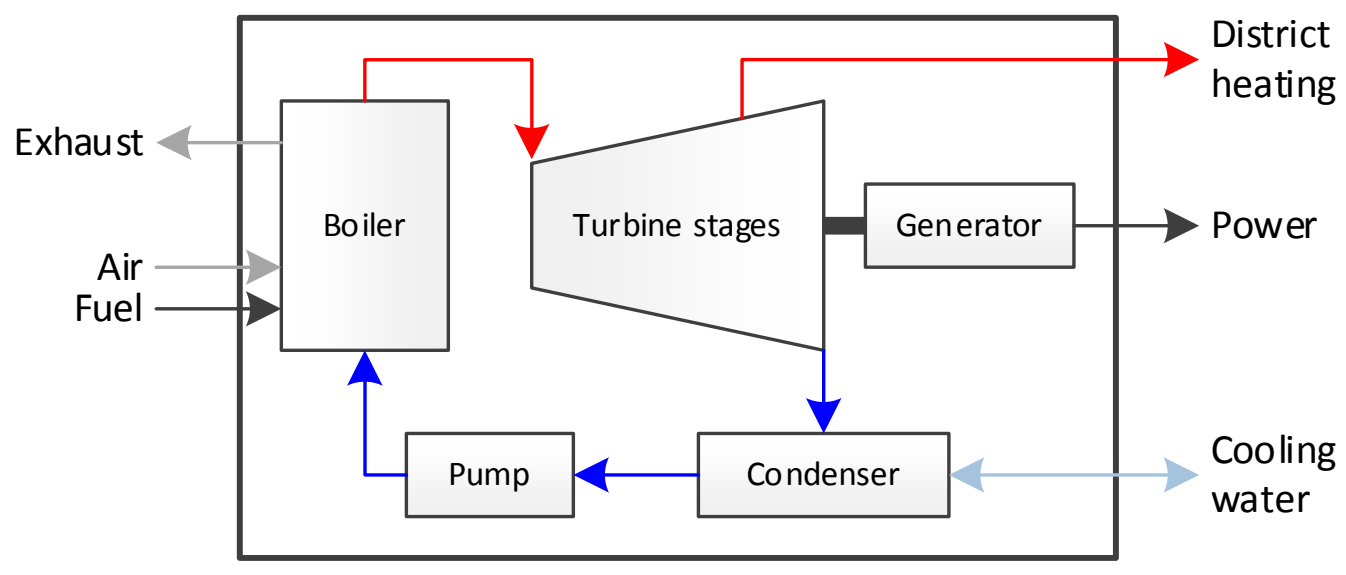


Figure 3 Caption

Figure 3 - Principal sketch of a Danish extraction-based CHP plant. 
Figure 4

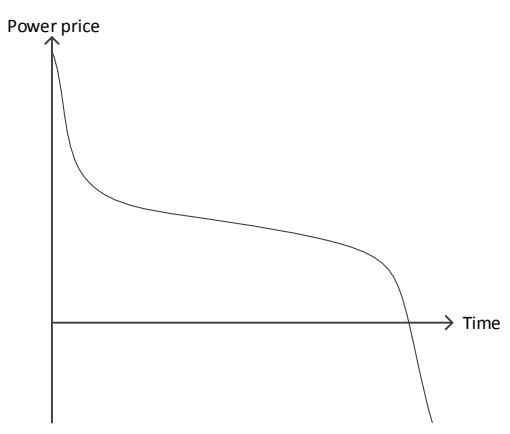

a) Power price

b) Power price
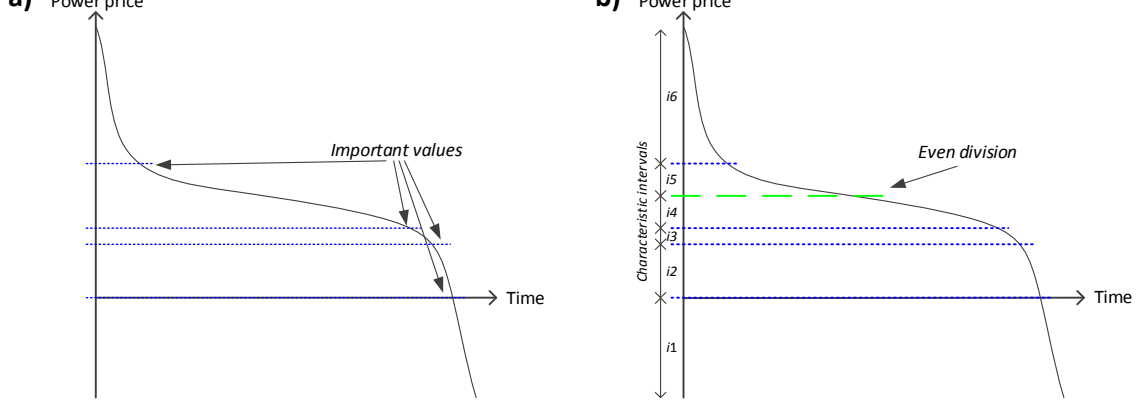
Figure 4 Caption

Figure 4 - Illustrative example of the suggested two-step approach for defining characteristic intervals based on the cumulative curve (left). Interval break points are set for a) Important values, and b) Even division. The characteristic intervals are indicated on the second axis in b). 
Figure 5
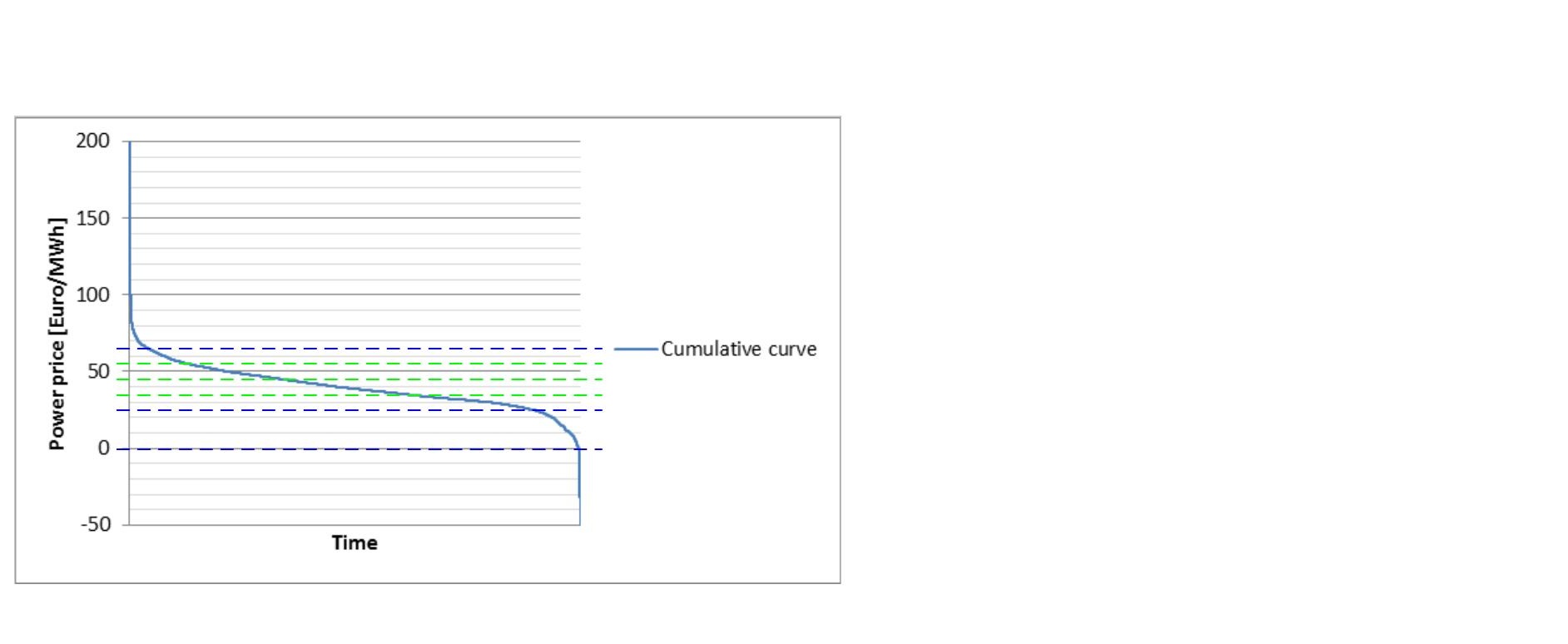

\section{5}

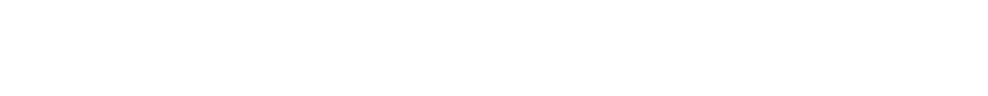




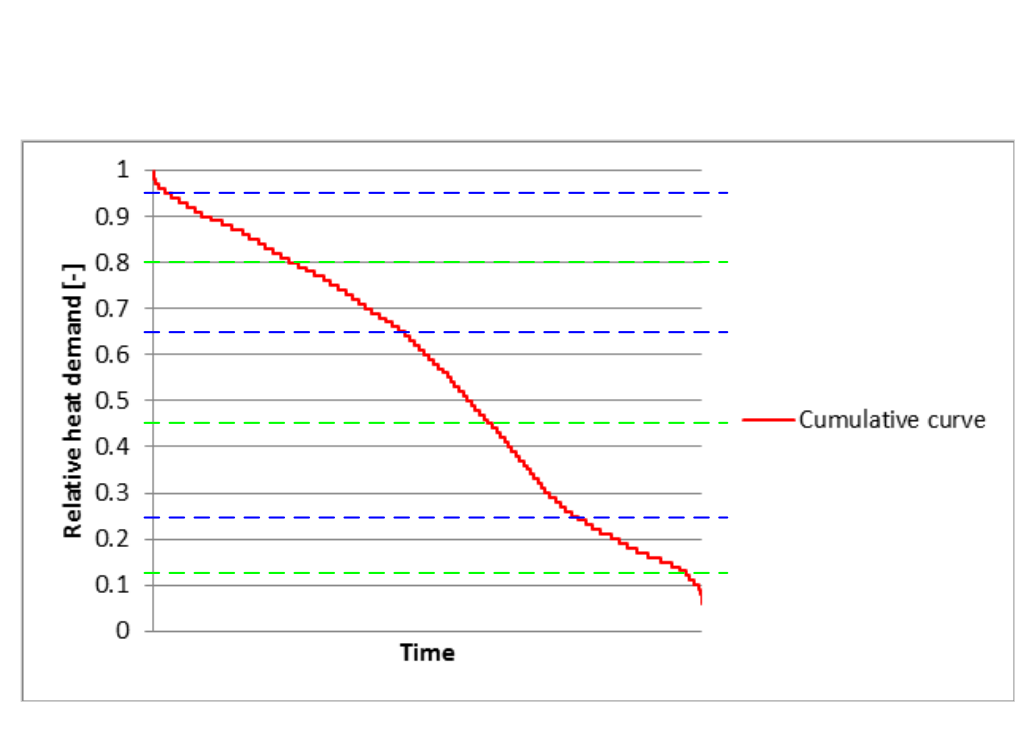

Figure 6

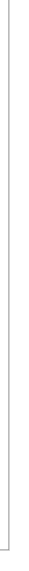

.

\section{6}

(

Figure
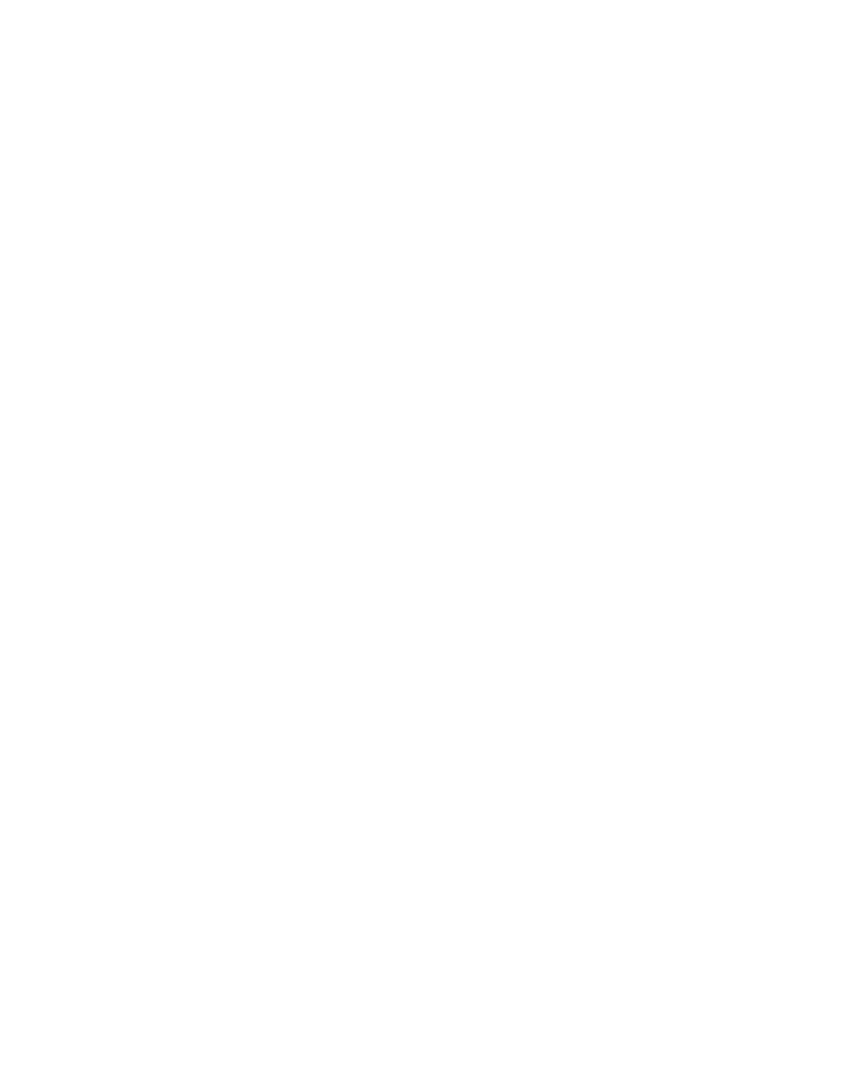
Figure 6 Caption

Figure 6 - Cumulative curve for the relative heat demand in Denmark over the period 2010-01-01 - 2014-
12-31, with interval break lines.

Figure 6 - Cumulative curve for the relative heat demand in Denmark over the period 2010-01-01-2014-
12-31, with interval break lines. (2-31, with interval break lines.

Figure 6 - Cumulative curve for the relative heat demand in Denmark over the period 2010-01-01 - 2014-
12-31, with interval break lines. .

$x^{2}$
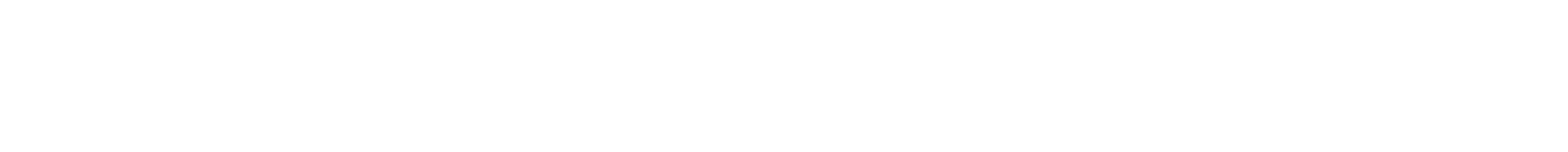
Figure 7

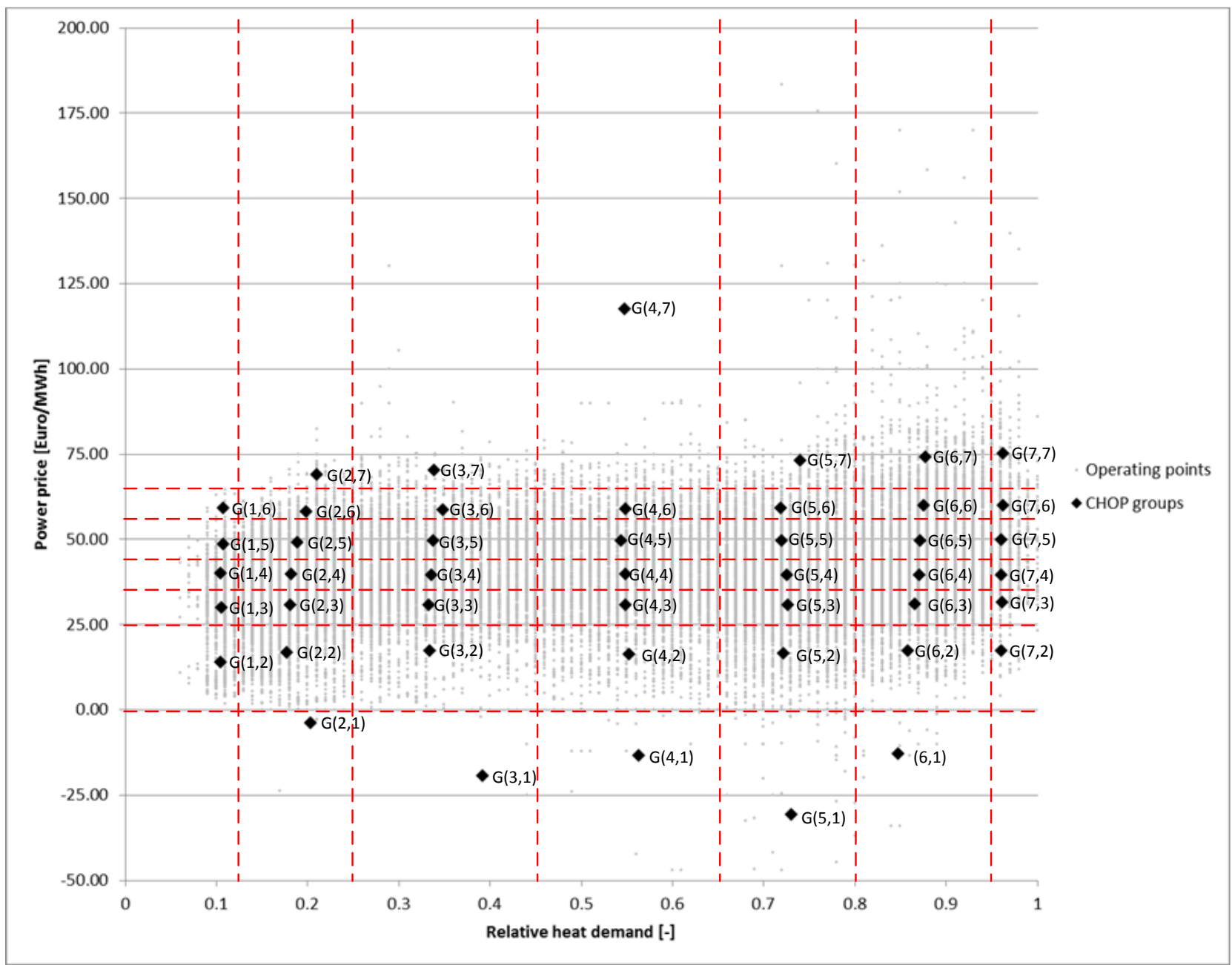


Figure 7 Caption

Figure 7 -Scatter diagram showing the reference operating points, characteristic interval breaks, and final CHOP groups. Notice that a small number of the reference operating points lies outside the power price boundaries of the diagram. 
Figure 8

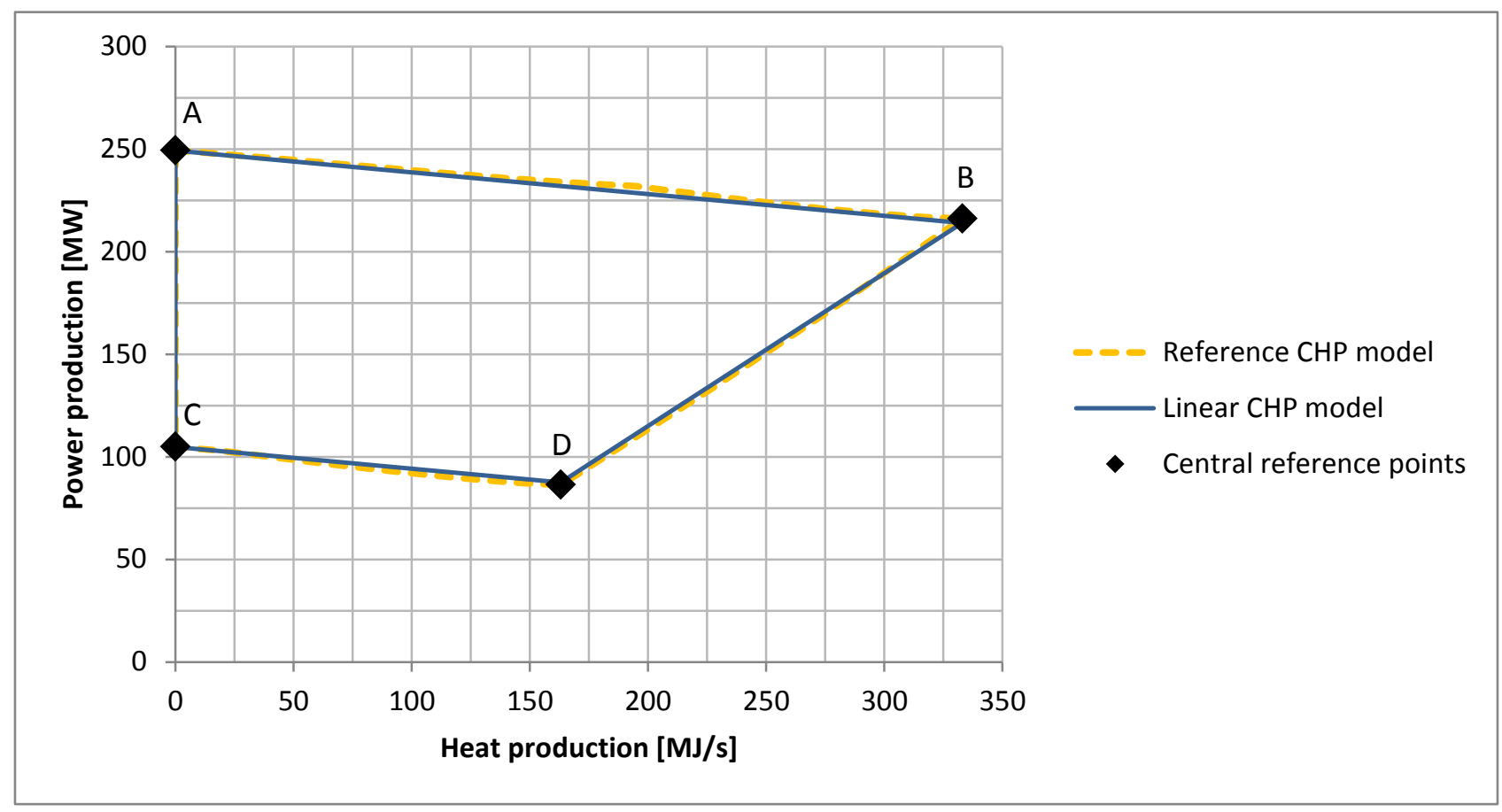


Figure 8 Caption

Figure 8- Heat and power production range of the reference CHP plant model [43] and the developed linearized model. The outlined areas represent the feasible production points of the models. Four central operating points $\{A, B, C, D\}$ are highlighted. Data for these operating points is presented in Table 6. 
Figure 9

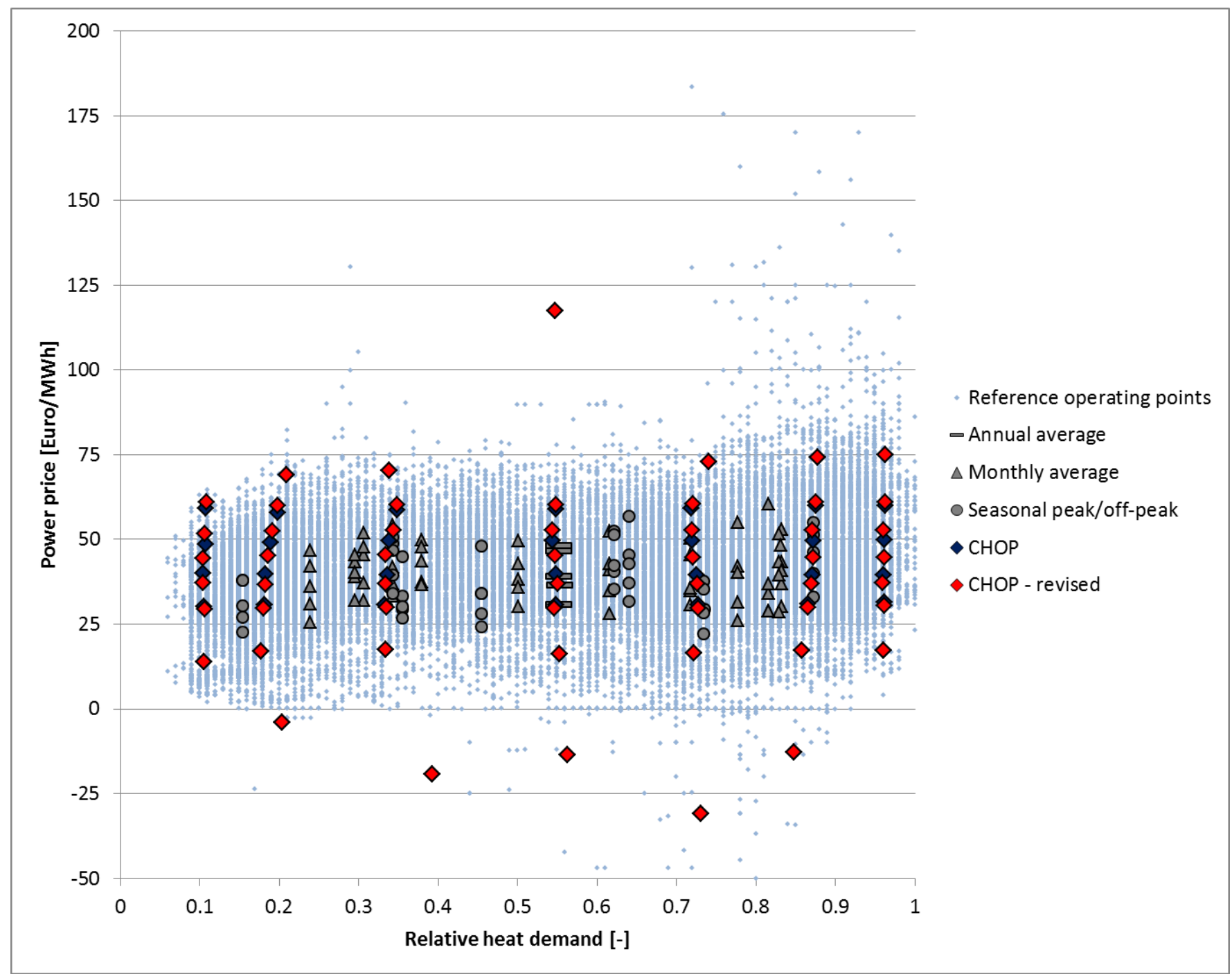


Figure 9 Caption

Figure 9 -Scatter diagram showing reference, annually averaged, monthly averaged, seasonal peak/offpeak, CHOP, and revised-CHOP operating points over the period 2010-01-01-2014-12-31. Notice that some of the $\mathrm{CHOP}$ and revised-CHOP operating points are overlapping. 


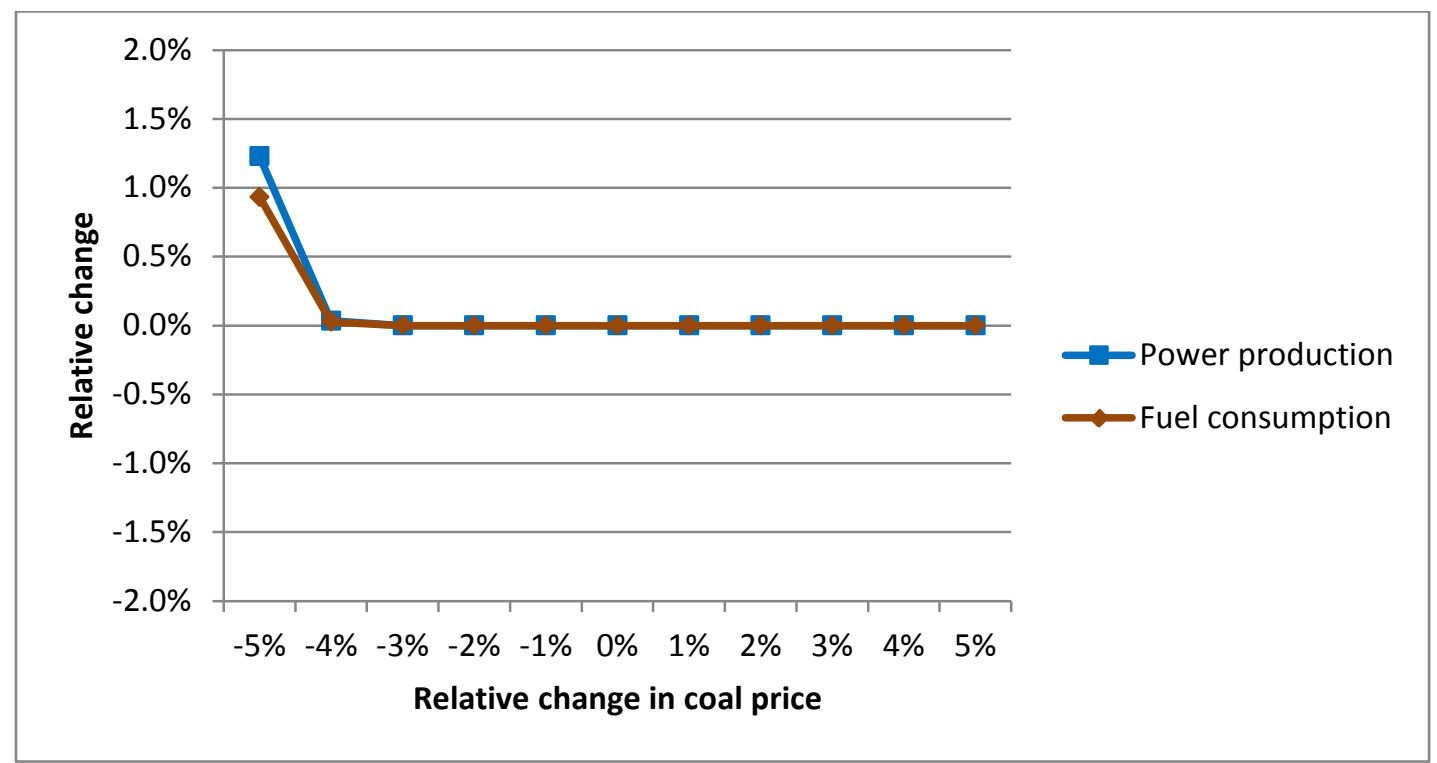


Figure 10 Caption

Figure 10 - Relative changes in optimized power production and fuel consumption as a function of relative changes in the coal price. Notice that heat production is unaffected by the coal price as it is constrained in the optimization model. 


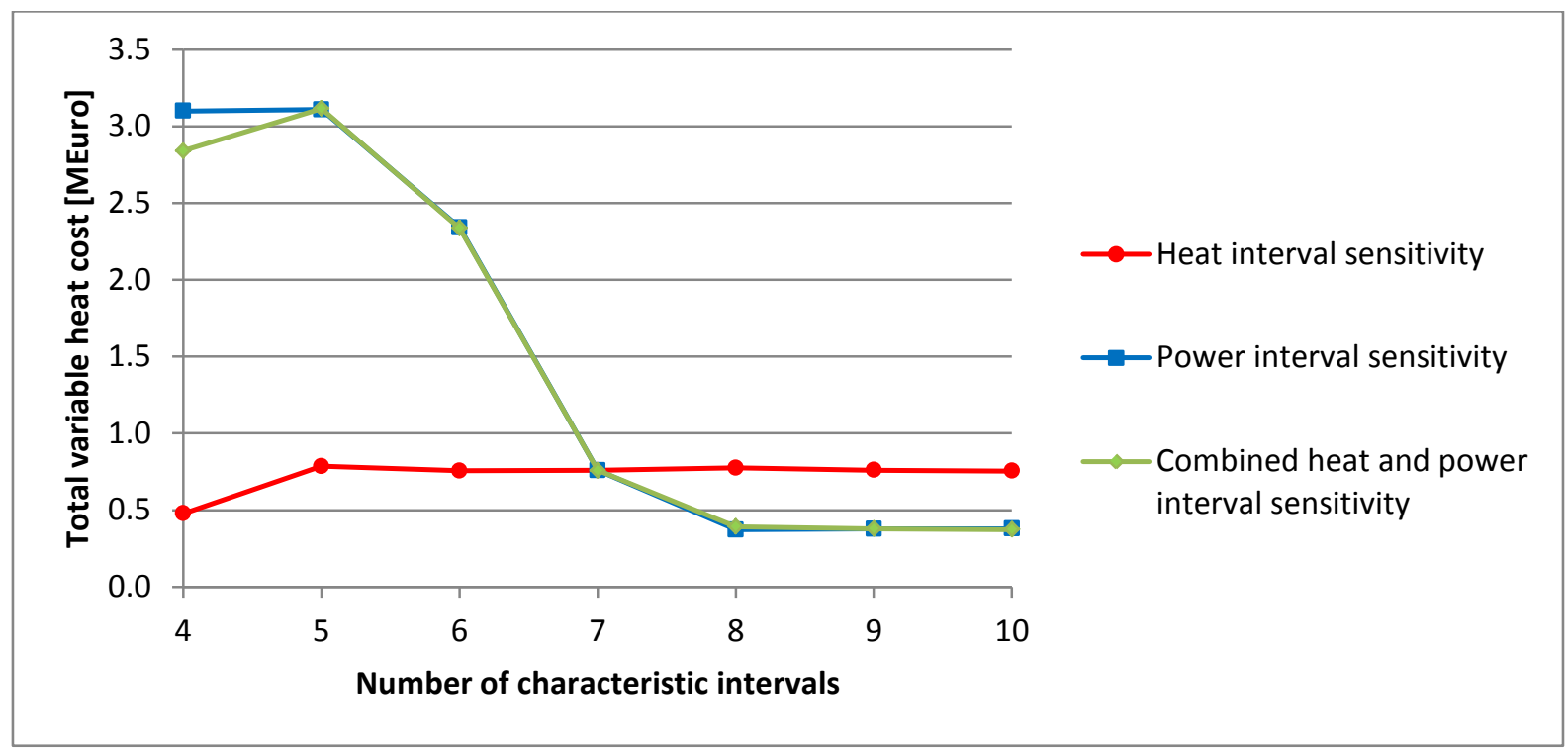


Figure 11 Caption

Figure 11- Totol varable heat cost sensitituty analysis.

Figure $11-$ Total variable heat cost sensitivity analysis.

.

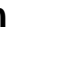

Figure $11-$ Total variable heat cost sensitivity analysis.

Figure 11 - Total variable heat cost sensitivity analysis.

Figure $11-$ Total variable heat cost sensitivity analysis.

(2)

Figure $11-$ Total variable heat cost sensitivity analysis.

Figure $11-$ Total variable heat cost sensitivity analysis.

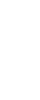

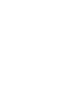

(n)

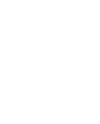

$\sqrt{2}+x^{2}$

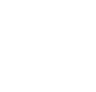

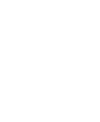
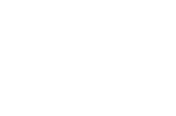

(1)
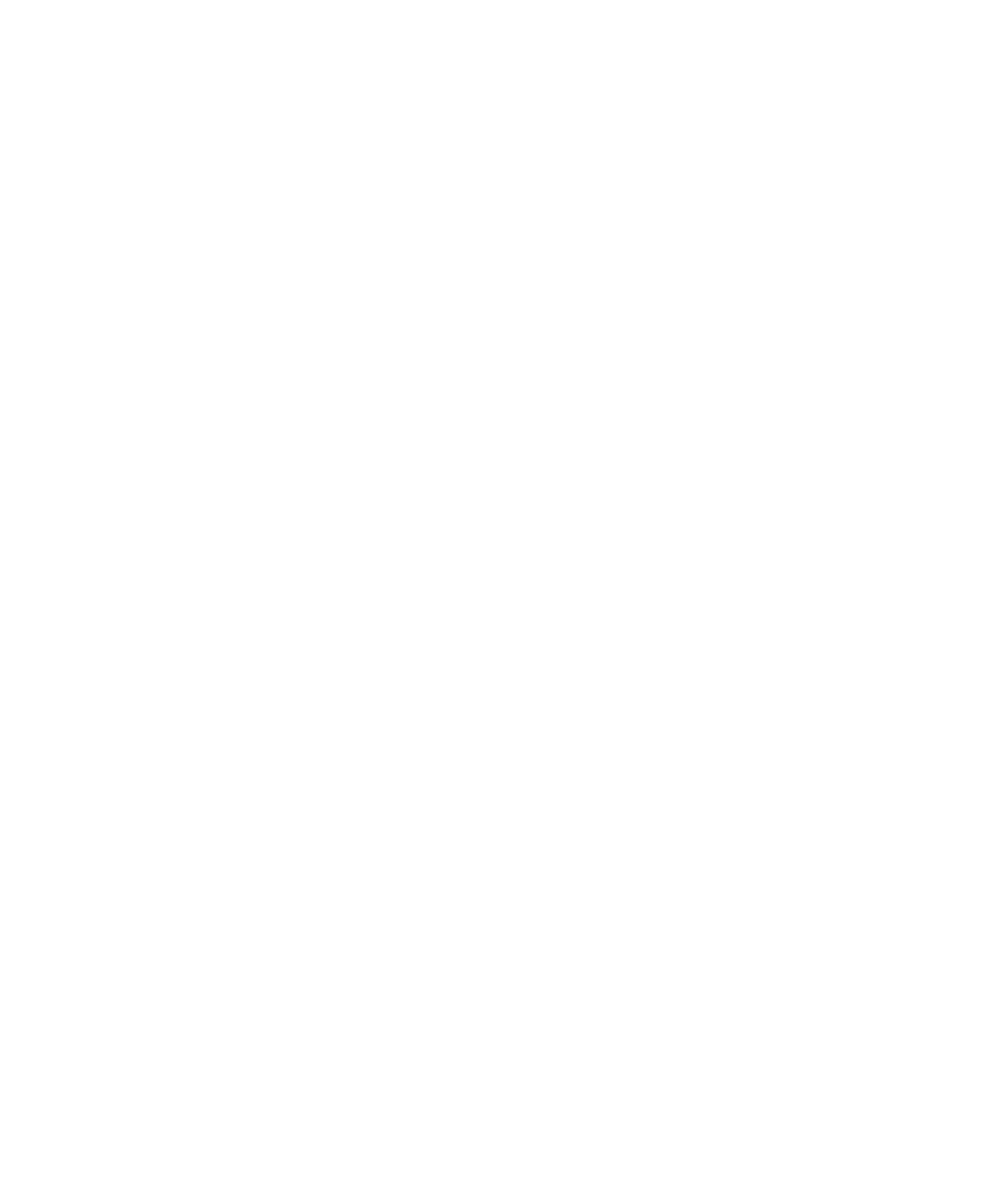


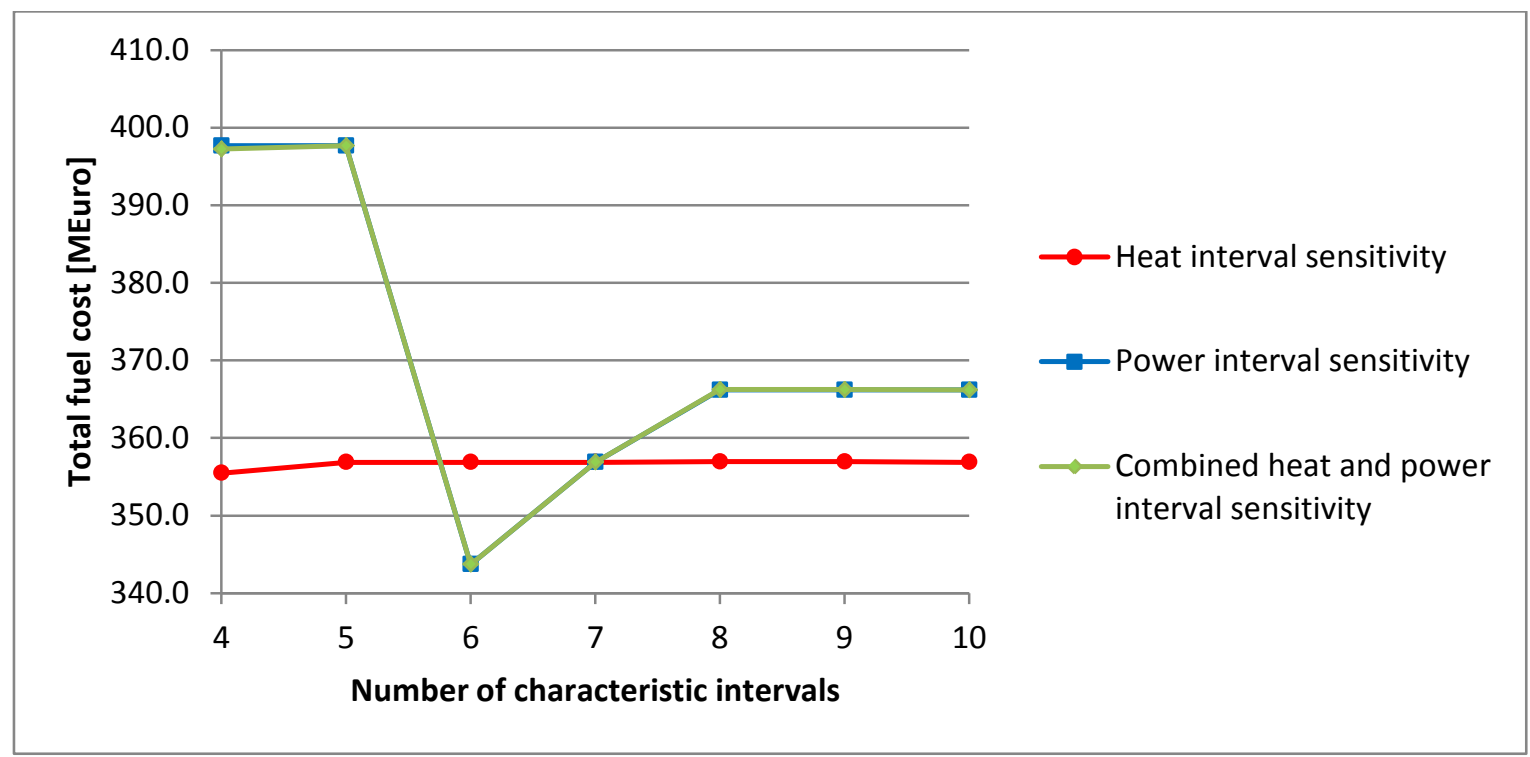


Figure 12 Caption

Figure $12-$ Total fuel cost sensitivity analysis.

Figure $12-$ Total fuel cost sensitivity analysis.

Figure $12-$ Total fuel cost sensitivity analysis.

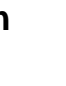

Figure $12-$ Total fuel cost sensitivity analysis.

$\sqrt{2}+n^{2}$

Figure $12-$ Total fuel cost sensitivity analysis.

Figure $12-$ Total fuel cost sensitivity analysis.

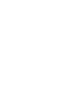

Figure $12-$ Total fuel cost sensitivity analysis.

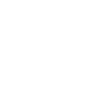

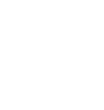

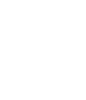

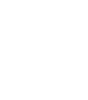

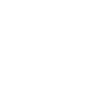

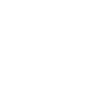

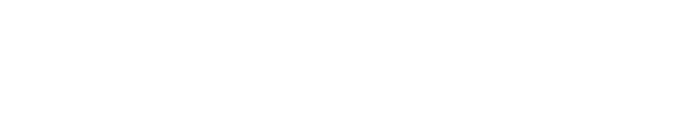

(1) 


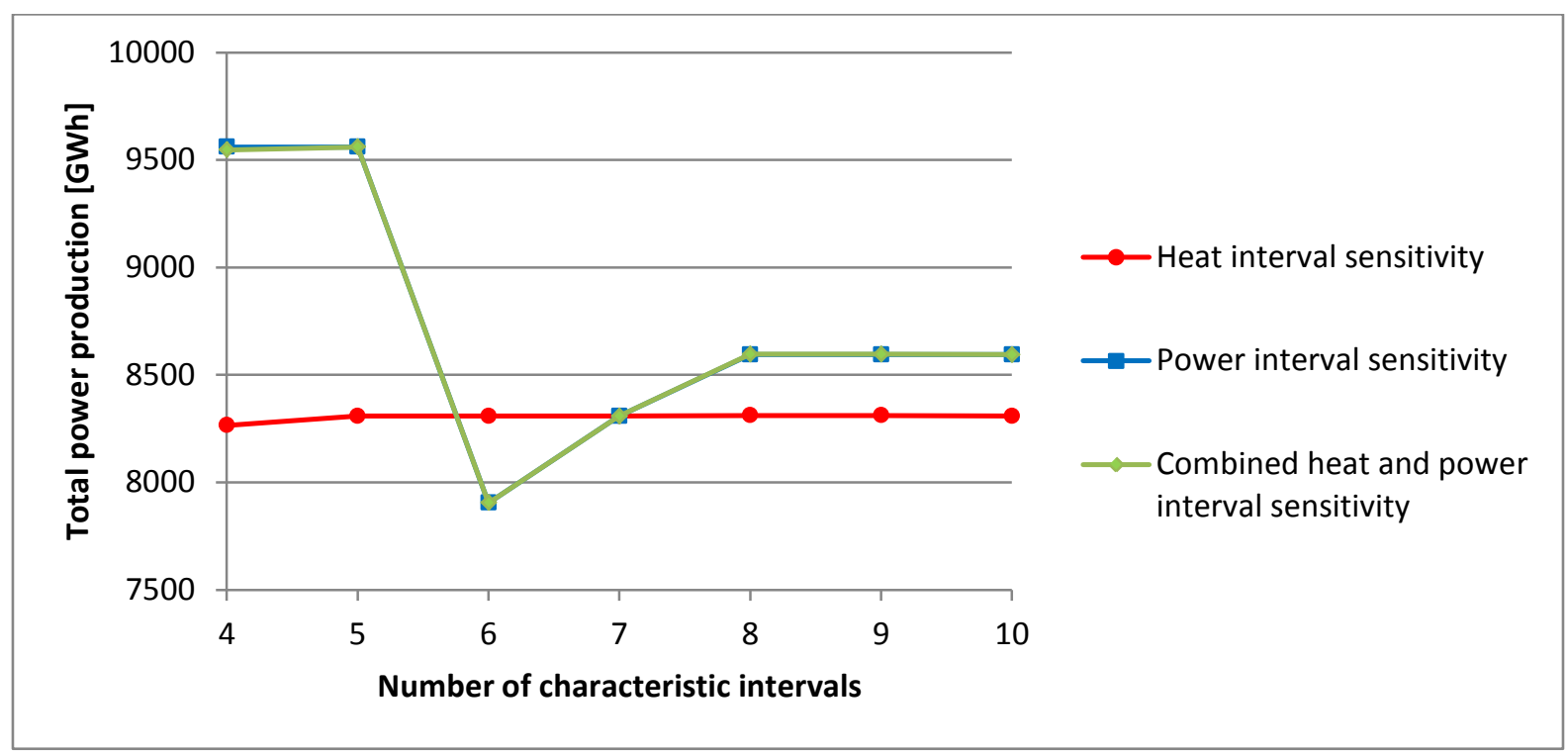


Figure 13 Caption

\footnotetext{
Figure 13 - Total power production sensitivity analysis.
} 


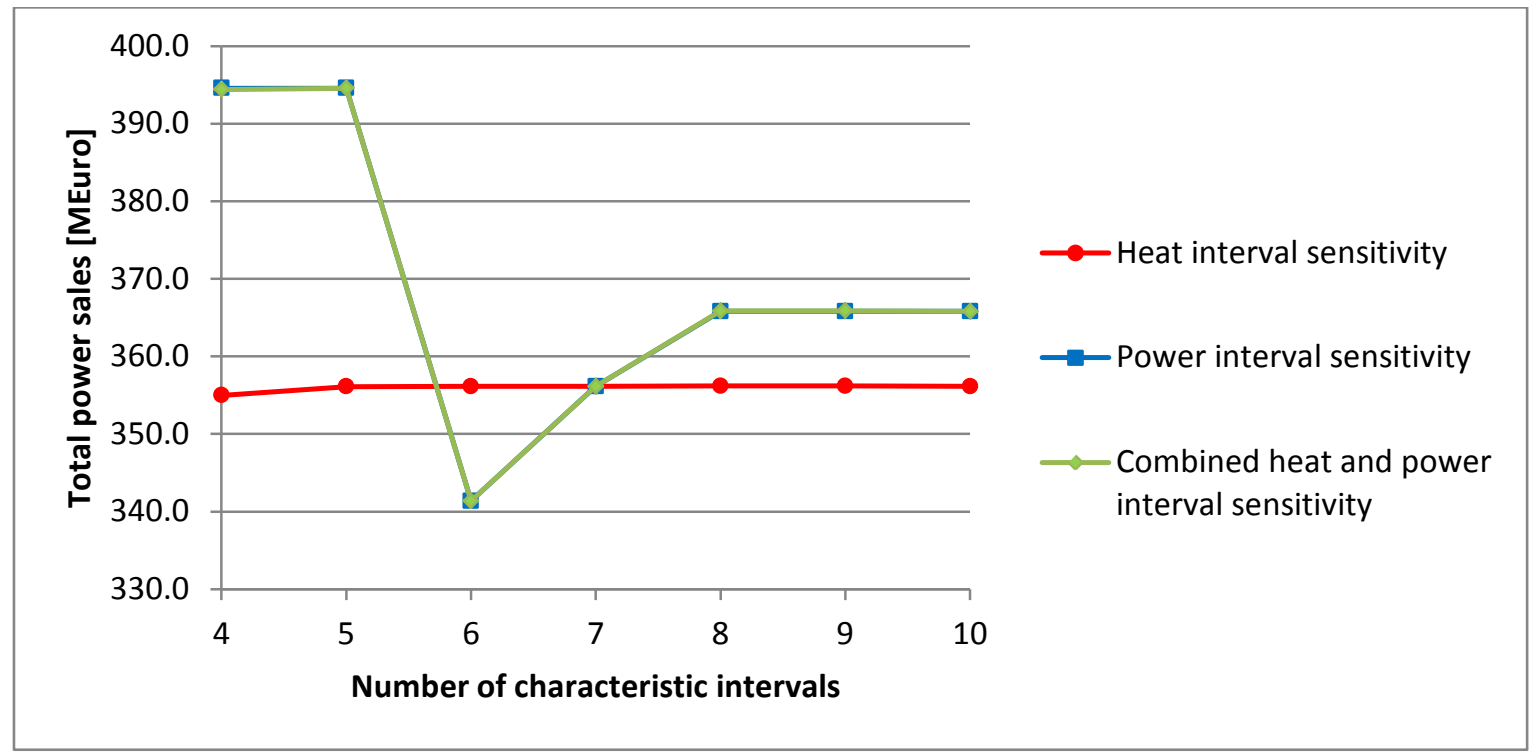


Figure 14 Caption

Figure 14 - Total power sales sensitivity analysis.

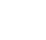

Fion

(n)

Figure 14 - Total power sales sensitivity analysis.

(1)

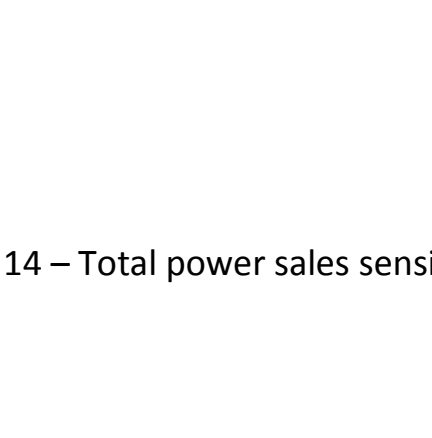

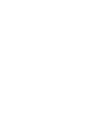

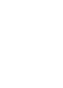

(1)

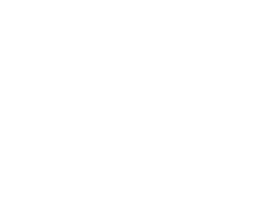

.
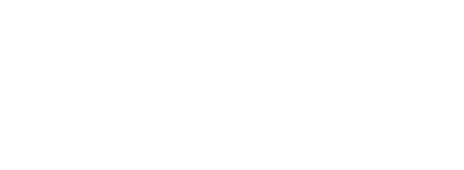
Figure 15

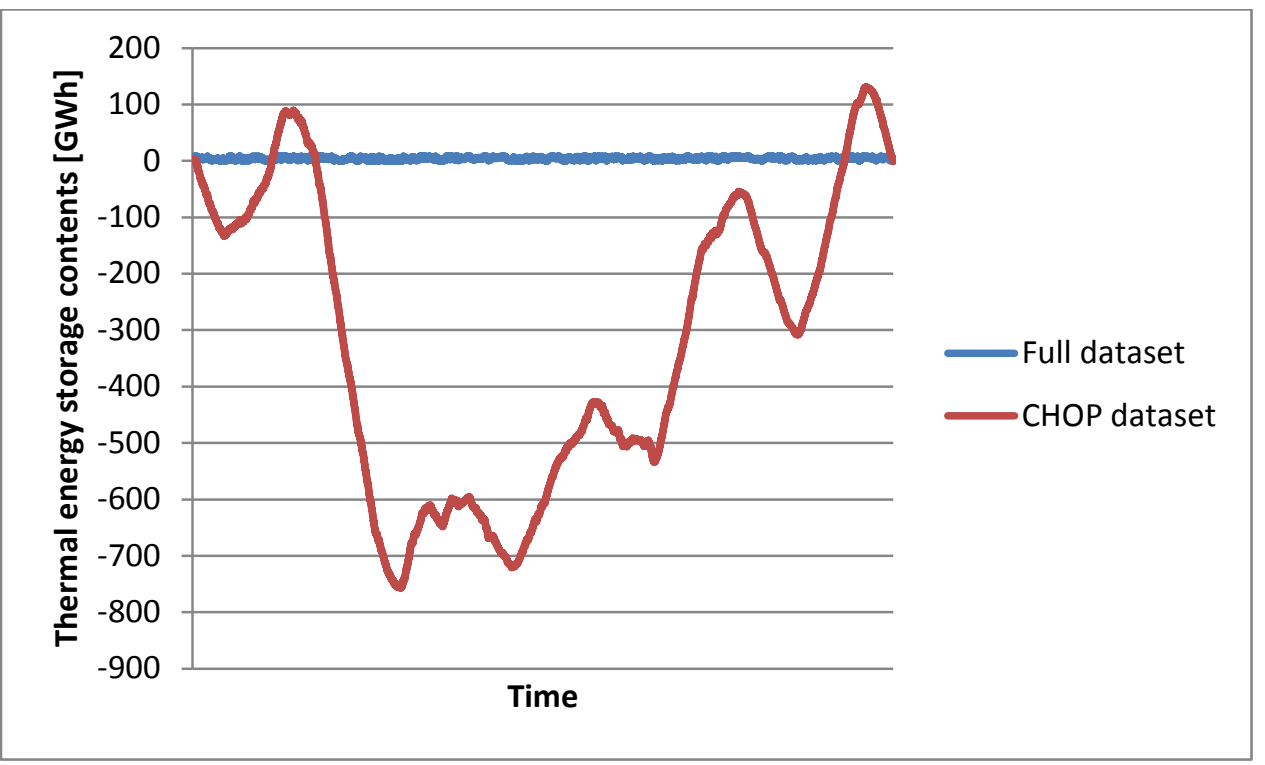


Figure 15 Caption

Figure 15 - Thermal energy storage contents over the 5-year period for the optimal solutions to problem (27) obtained using the full EOC dataset and the revised CHOP dataset. 
Table 1 - Characteristic power price intervals.

\begin{tabular}{|l|l|l|}
\hline Power price interval number $i$ & Smallest value [Euro/MWh] & Largest value [Euro/MWh] \\
\hline 1 & $-\infty^{\text {a }}$ & -0.01 \\
\hline 2 & 0.00 & 24.99 \\
\hline 3 & 25.00 & 34.99 \\
\hline 4 & 35.00 & 44.99 \\
\hline 5 & 45.00 & 54.99 \\
\hline 6 & 55.00 & 64.99 \\
\hline 7 & 65.00 & $\infty^{\text {a }}$ \\
\hline
\end{tabular}

${ }^{a}$ Notice that the intervals are defined as open towards the infinite to cover all feasible power prices 
Table 2 - Characteristic heat demand intervals.

\begin{tabular}{|c|c|c|}
\hline Heat demand interval number $i$ & Smallest value [-] & Largest value [-] \\
\hline 1 & 0.000 & 0.124 \\
\hline 2 & 0.125 & 0.249 \\
\hline 3 & 0.250 & 0.649 \\
\hline 4 & 0.450 & 0.799 \\
\hline 5 & 0.650 & 0.949 \\
\hline 6 & 0.800 & 1.000 \\
\hline 7 & 0.950 & \\
\hline
\end{tabular}


Table 3 - Characteristics of the defined CHOP groups.

\begin{tabular}{|c|c|c|c|c|c|c|c|}
\hline \multicolumn{8}{|c|}{ CHOP group characteristics } \\
\hline \multirow{2}{*}{$\begin{array}{r}\text { Duration [h] } \\
\text { Heat interval }\end{array}$} & \multicolumn{7}{|c|}{ Power interval } \\
\hline & 1 & 2 & 3 & 4 & 5 & 6 & 7 \\
\hline 1 & 0 & 321 & 427 & 390 & 136 & 16 & 0 \\
\hline 2 & 11 & 1178 & 2812 & 2327 & 1838 & 379 & 55 \\
\hline 3 & 9 & 615 & 1808 & 1826 & 1739 & 640 & 178 \\
\hline 4 & 22 & 717 & 1847 & 1828 & 1672 & 741 & 198 \\
\hline 5 & 72 & 947 & 2380 & 2436 & 1649 & 803 & 273 \\
\hline 6 & 30 & 582 & 2608 & 2932 & 1871 & 1158 & 903 \\
\hline 7 & 0 & 46 & 262 & 442 & 272 & 217 & 211 \\
\hline \multicolumn{8}{|c|}{ Relative heat demand [-] } \\
\hline 1 & - & 0.105 & 0.106 & 0.104 & 0.107 & 0.108 & - \\
\hline 2 & 0.204 & 0.178 & 0.181 & 0.183 & 0.189 & 0.199 & 0.210 \\
\hline 3 & 0.392 & 0.334 & 0.333 & 0.336 & 0.338 & 0.348 & 0.339 \\
\hline 4 & 0.563 & 0.553 & 0.548 & 0.549 & 0.544 & 0.549 & 0.547 \\
\hline 5 & 0.731 & 0.721 & 0.727 & 0.726 & 0.720 & 0.719 & 0.740 \\
\hline 6 & 0.848 & 0.858 & 0.866 & 0.871 & 0.872 & 0.875 & 0.878 \\
\hline 7 & - & 0.961 & 0.961 & 0.960 & 0.961 & 0.963 & 0.963 \\
\hline \multicolumn{8}{|c|}{ Power price [Euro/MWh] } \\
\hline 1 & - & 13.91 & 30.06 & 40.14 & 48.52 & 59.09 & - \\
\hline 2 & -3.92 & 16.86 & 30.65 & 39.70 & 49.04 & 58.00 & 69.02 \\
\hline 3 & -19.24 & 17.43 & 30.77 & 39.43 & 49.58 & 58.53 & 70.32 \\
\hline
\end{tabular}




\begin{tabular}{|l|c|c|c|c|c|c|c|}
\hline $\mathbf{4}$ & -13.46 & 16.22 & 30.78 & 39.78 & 49.48 & 58.99 & 117.54 \\
\hline $\mathbf{5}$ & -30.81 & 16.58 & 30.73 & 39.54 & 49.58 & 59.13 & 72.97 \\
\hline $\mathbf{6}$ & -12.90 & 17.36 & 31.01 & 39.58 & 49.60 & 59.90 & 74.10 \\
\hline $\mathbf{7}$ & - & 17.20 & 31.54 & 39.56 & 49.74 & 60.00 & 75.08 \\
\hline
\end{tabular}


Table 4-CHOP group relative heat demand standard deviation, $\sigma_{\lambda_{\text {heat }}}$.

\begin{tabular}{|l|c|c|c|c|c|c|c|}
\hline CHOP group $\sigma_{\lambda_{\text {heat }}}[-]$ & & & & & & & \\
Heat interval \power interval & 1 & 2 & 3 & 4 & 5 & 6 & 7 \\
\hline 1 & & & & & & & \\
\hline 2 & 0.026 & 0.032 & 0.032 & 0.033 & 0.031 & 0.029 & 0.020 \\
\hline 3 & 0.065 & 0.058 & 0.059 & 0.060 & 0.061 & 0.058 & 0.059 \\
\hline 4 & 0.055 & 0.058 & 0.058 & 0.058 & 0.059 & 0.060 & 0.061 \\
\hline 5 & 0.040 & 0.041 & 0.044 & 0.044 & 0.043 & 0.045 & 0.044 \\
\hline 6 & 0.038 & 0.042 & 0.042 & 0.042 & 0.042 & 0.042 & 0.042 \\
\hline 7 & - & 0.011 & 0.013 & 0.012 & 0.013 & 0.014 & 0.013 \\
\hline
\end{tabular}


Table 5 - CHOP group power price standard deviation, $\sigma_{c_{\text {power }}}$.

\begin{tabular}{|l|c|c|c|c|c|c|c|}
\hline CHOP group $\sigma_{c_{\text {power }}}$ & & & & & & & \\
[Euro/MWh] & 1 & 2 & 3 & 4 & 5 & 6 & 7 \\
Heat interval \power interval & & & & & & & \\
\hline 1 & & & & & & & \\
\hline 2 & - & 6.57 & 2.70 & 2.80 & 2.37 & 3.14 & - \\
\hline 3 & 6.35 & 6.45 & 2.63 & 2.90 & 2.76 & 2.67 & 3.61 \\
\hline 4 & 21.67 & 6.64 & 2.66 & 2.89 & 2.82 & 2.82 & 7.49 \\
\hline 5 & 16.79 & 6.91 & 2.70 & 2.87 & 2.78 & 2.82 & 293.62 \\
\hline 6 & 55.98 & 7.23 & 2.64 & 2.87 & 2.91 & 2.75 & 14.17 \\
\hline 7 & 16.10 & 6.42 & 2.54 & 2.78 & 2.86 & 3.07 & 13.46 \\
\hline
\end{tabular}


Table 6-Data on four central reference points $\{A, B, C, D\}$ in the reference model of AVV1 [43], and their corresponding points $\left\{A^{*}, B^{*}, C^{*}, D^{*}\right\}$ in the linearized model of AVV1.

\begin{tabular}{|c|c|c|c|c|}
\hline Point, $j$ & Load, $\lambda$ & Back-pressure ratio, $\alpha$ & Power production, $P_{j}[\mathrm{MW}]$ & Heat production, $Q_{j}[\mathrm{MJ} / \mathrm{s}]$ \\
\hline A & 1.0 & 0.0 & 249.3 & 0.0 \\
\hline A $^{*}$ & 1.0 & 0.0 & 249.3 & 0.0 \\
\hline B & 1.0 & 1.0 & 216.0 & 332.9 \\
\hline B $^{*}$ & 1.0 & 1.0 & 213.9 & 332.9 \\
\hline C & 0.4 & 0.0 & 104.9 & 0.0 \\
\hline C* & 0.4 & 0.0 & 104.9 & 0.0 \\
\hline D & 0.4 & 1.0 & 86.3 & 163.1 \\
\hline D* & 0.4 & 1.0 & 87.5 & 163.1 \\
\hline
\end{tabular}


Table 7-Optimization results obtained using the five different EOC datasets.

\begin{tabular}{|l|c|c|c|c|c|}
\hline & Full & Annually & Monthly & Seasonal & CHOP- \\
& dataset & averaged & averaged & peak/off-peak & reduced \\
\hline RESULTS & & & & & \\
\hline Total variable heat cost, $C_{\text {heat }}$ [MEuro] & 0.38 & 8.53 & 8.02 & 5.96 & 0.76 \\
\hline Total power sales [MEuro] & 368.06 & 369.51 & 376.62 & 370.41 & 356.12 \\
\hline Total fuel costs [MEuro] & 368.44 & 377.81 & 384.64 & 376.38 & 356.88 \\
\hline PRODUCTION DATA & & & & & 8,066 \\
\hline Total heat production [GWh] & 8,066 & 8,066 & 8,066 & 8,066 & 8,309 \\
\hline Total power production [GWh] & 8,664 & 8,958 & 9,161 & 8,907 & 22,724 \\
\hline Total fuel consumption [GWh] & 23,460 & 24,057 & 24,492 & 23,966 & \\
\hline OPTIMIZATION PROBLEM & & & & & \\
\hline Number of periods & 43,824 & 5 & 60 & 40 & 46 \\
\hline Variables per period & 2 & 2 & 2 & 2 & \\
\hline Constraints per period & & 4 & 4 & & \\
\hline
\end{tabular}


Table 8-Interval break points as a function of the number of intervals defined.

\begin{tabular}{|c|c|c|c|c|c|c|c|}
\hline No. of intervals & 4 & 5 & 6 & 7 & 8 & 9 & 10 \\
\hline Relative heat demand interval breaks [-] & $\begin{array}{l}0.25 \\
0.65 \\
0.95\end{array}$ & $\begin{array}{l}0.25 \\
0.45 \\
0.65 \\
0.95\end{array}$ & $\begin{array}{l}0.25 \\
0.45 \\
0.65 \\
0.80 \\
0.95\end{array}$ & $\begin{array}{l}0.125 \\
0.25 \\
0.45 \\
0.65 \\
0.80 \\
0.95\end{array}$ & $\begin{array}{l}0.125 \\
0.25 \\
0.38 \\
0.52 \\
0.65 \\
0.80 \\
0.95\end{array}$ & $\begin{array}{l}0.125 \\
0.25 \\
0.38 \\
0.52 \\
0.65 \\
0.75 \\
0.85 \\
0.95\end{array}$ & $\begin{array}{l}0.125 \\
0.25 \\
0.35 \\
0.45 \\
0.55 \\
0.65 \\
0.75 \\
0.85 \\
0.95\end{array}$ \\
\hline Power price interval breaks [Euro/MWh] & $\begin{array}{l}0.00 \\
25.00 \\
65.00\end{array}$ & $\begin{array}{l}0.00 \\
25.00 \\
45.00 \\
65.00\end{array}$ & $\begin{array}{l}0.00 \\
25.00 \\
38.00 \\
52.00 \\
65.00\end{array}$ & $\begin{array}{l}0.00 \\
25.00 \\
35.00 \\
45.00 \\
55.00 \\
65.00\end{array}$ & $\begin{array}{l}0.00 \\
25.00 \\
33.00 \\
41.00 \\
49.00 \\
57.00 \\
65.00\end{array}$ & $\begin{array}{l}0.00 \\
12.50 \\
25.00 \\
33.00 \\
41.00 \\
49.00 \\
57.00 \\
65.00\end{array}$ & $\begin{array}{l}0.00 \\
8.00 \\
17.00 \\
25.00 \\
33.00 \\
41.00 \\
49.00 \\
57.00 \\
65.00\end{array}$ \\
\hline
\end{tabular}


Table 9-Characteristics of the revised CHOP groups.

\begin{tabular}{|c|c|c|c|c|c|c|c|c|}
\hline \multicolumn{9}{|c|}{ CHOP group characteristics } \\
\hline \multirow{2}{*}{$\begin{array}{r}\text { Duration [h] } \\
\text { Heat interval }\end{array}$} & \multicolumn{8}{|c|}{ Power interval } \\
\hline & 1 & 2 & 3 & 4 & 5 & 6 & 7 & 8 \\
\hline 1 & 0 & 321 & 356 & 306 & 242 & 55 & 10 & 0 \\
\hline 2 & 11 & 1178 & 2198 & 2111 & 1872 & 980 & 195 & 55 \\
\hline 3 & 9 & 615 & 1383 & 1673 & 1400 & 1150 & 407 & 178 \\
\hline 4 & 22 & 717 & 1402 & 1600 & 1483 & 1085 & 518 & 198 \\
\hline 5 & 72 & 947 & 1824 & 2163 & 1565 & 1139 & 577 & 273 \\
\hline 6 & 30 & 582 & 1953 & 2641 & 1776 & 1301 & 898 & 903 \\
\hline 7 & 0 & 46 & 189 & 365 & 267 & 195 & 177 & 211 \\
\hline \multicolumn{9}{|c|}{ Relative heat demand [-] } \\
\hline 1 & - & 0.105 & 0.106 & 0.105 & 0.105 & 0.107 & 0.109 & - \\
\hline 2 & 0.204 & 0.178 & 0.180 & 0.182 & 0.186 & 0.191 & 0.199 & 0.210 \\
\hline 3 & 0.392 & 0.334 & 0.335 & 0.334 & 0.334 & 0.344 & 0.348 & 0.339 \\
\hline 4 & 0.563 & 0.553 & 0.546 & 0.550 & 0.547 & 0.544 & 0.549 & 0.547 \\
\hline 5 & 0.731 & 0.721 & 0.727 & 0.726 & 0.721 & 0.720 & 0.721 & 0.740 \\
\hline 6 & 0.848 & 0.858 & 0.866 & 0.870 & 0.872 & 0.871 & 0.876 & 0.878 \\
\hline 7 & - & 0.961 & 0.961 & 0.960 & 0.962 & 0.961 & 0.963 & 0.963 \\
\hline \multicolumn{9}{|c|}{ Power price [Euro/MWh] } \\
\hline 1 & - & 13.91 & 29.32 & 37.20 & 44.49 & 51.62 & 61.11 & - \\
\hline 2 & -3.92 & 16.86 & 29.73 & 36.73 & 45.20 & 52.51 & 60.05 & 69.02 \\
\hline 3 & -19.24 & 17.43 & 29.80 & 36.80 & 45.40 & 52.64 & 60.23 & 70.32 \\
\hline
\end{tabular}




\begin{tabular}{|l|c|c|c|c|c|c|c|c|}
\hline $\mathbf{4}$ & -13.46 & 16.22 & 29.77 & 36.83 & 45.20 & 52.59 & 60.34 & 117.54 \\
\hline $\mathbf{5}$ & -30.81 & 16.58 & 29.75 & 36.82 & 44.74 & 52.63 & 60.39 & 72.97 \\
\hline $\mathbf{6}$ & -12.90 & 17.36 & 30.03 & 36.98 & 44.76 & 52.59 & 61.08 & 74.10 \\
\hline $\mathbf{7}$ & - & 17.20 & 30.56 & 37.11 & 44.58 & 52.75 & 60.95 & 75.08 \\
\hline
\end{tabular}


Table 10 - Optimization results obtained using the CHOP and the revised CHOP EOC datasets.

\begin{tabular}{|c|c|c|c|}
\hline & Full dataset & CHOP & CHOP-revised \\
\hline \multicolumn{4}{|l|}{ RESULTS } \\
\hline Total variable heat cost, $C_{\text {heat }}$ [MEuro] & 0.38 & 0.76 & 0.37 \\
\hline Total power sales [MEuro] & 368.06 & 356.12 & 365.81 \\
\hline Total fuel costs [MEuro] & 368.44 & 356.88 & 366.18 \\
\hline \multicolumn{4}{|l|}{ PRODUCTION DATA } \\
\hline Total heat production [GWh] & 8,066 & 8,066 & 8,066 \\
\hline Total power production [GWh] & 8,664 & 8,309 & 8,594 \\
\hline Total fuel consumption [GWh] & 23,460 & 22,724 & 23,317 \\
\hline \multicolumn{4}{|l|}{ OPTIMIZATION PROBLEM } \\
\hline Number of periods & 43,824 & 46 & 53 \\
\hline Variables per period & 2 & 2 & 2 \\
\hline Constraints per period & 4 & 4 & 4 \\
\hline
\end{tabular}


Table 11 - Optimization results obtained from solving optimization problem (28) using the full EOC dataset and the revised $\mathrm{CHOP}$ dataset.

\begin{tabular}{|l|l|l|l|}
\hline & Full dataset & Full dataset & CHOP-revised \\
& Problem (22) & Problem (28) & Problem (28) \\
\hline RESULTS & & & \\
\hline Total variable heat cost, $C_{\text {heat }}$ [MEuro] & 0.38 & -6.08 & -8.06 \\
\hline Total power sales [MEuro] & 368.06 & 372.50 & 357.04 \\
\hline Total fuel costs [MEuro] & 368.44 & 366.42 & 348.97 \\
\hline PRODUCTION DATA & & & 8,066 \\
\hline Total heat production [GWh] & 8,066 & 8,066 & 8,066 \\
\hline Total power production [GWh] & 8,664 & 8,602 & 22,221 \\
\hline Total fuel consumption [GWh] & 23,460 & 23,332 & 5 \\
\hline OPTIMIZATION PROBLEM & & 43,824 & 2 \\
\hline Number of periods & 43,824 & 2 & 53 \\
\hline Variables per period & 2 & 6 & \\
\hline Constraints per period & 4 & & \\
\hline
\end{tabular}

"Constraints (26) and (27) were slacked when solving optimization problem (28) using the CHOP-revised dataset. 
Table 12 - Annually averaged EOC dataset, $D_{A A}$.

\begin{tabular}{|l|l|l|l|}
\hline Year & Duration $[\mathrm{h}]$ & $\begin{array}{l}\text { Power price, } c_{p, j} \\
{[\text { Euro/MWh] }}\end{array}$ & $\begin{array}{l}\text { Relative heat demand, } q_{j} \\
{[-]}\end{array}$ \\
\hline 2010 & 8760 & 46.48 & 0.553 \\
\hline 2011 & 8760 & 47.96 & 0.553 \\
\hline 2012 & 8784 & 36.33 & 0.554 \\
\hline 2013 & 8760 & 38.98 & 0.553 \\
\hline 2014 & 8760 & 30.67 & 0.553 \\
\hline
\end{tabular}


Table 13 - Monthly averaged EOC dataset, $D_{M A}$, period duration.

\begin{tabular}{|l|c|c|c|c|c|}
\hline Duration [h] & $\mathbf{2 0 1 0}$ & $\mathbf{2 0 1 1}$ & $\mathbf{2 0 1 2}$ & $\mathbf{2 0 1 3}$ & $\mathbf{2 0 1 4}$ \\
\hline January & 744 & 744 & 744 & 744 & 744 \\
\hline February & 672 & 672 & 696 & 672 & 672 \\
\hline March & 744 & 744 & 744 & 744 & 744 \\
\hline April & 720 & 720 & 720 & 720 & 720 \\
\hline May & 744 & 744 & 744 & 744 & 744 \\
\hline June & 720 & 720 & 720 & 720 & 720 \\
\hline July & 744 & 744 & 744 & 744 & 744 \\
\hline August & 744 & 744 & 744 & 744 & 744 \\
\hline September & 720 & 720 & 720 & 720 & 720 \\
\hline October & 744 & 744 & 744 & 744 & 744 \\
\hline November & 720 & 720 & 720 & 720 & 720 \\
\hline December & 744 & 744 & 744 & 744 & 744 \\
\hline
\end{tabular}


Table 14 - Monthly averaged EOC dataset, $D_{M A}$, period power price.

\begin{tabular}{|l|c|c|c|c|c|}
\hline Power price [Euro/MWh] & $\mathbf{2 0 1 0}$ & $\mathbf{2 0 1 1}$ & $\mathbf{2 0 1 2}$ & $\mathbf{2 0 1 3}$ & $\mathbf{2 0 1 4}$ \\
\hline January & 43.29 & 52.89 & 37.01 & 40.77 & 30.26 \\
\hline February & 43.45 & 51.75 & 48.35 & 39.40 & 28.74 \\
\hline March & 42.09 & 55.14 & 31.51 & 40.33 & 26.05 \\
\hline April & 41.11 & 52.33 & 34.76 & 42.82 & 28.13 \\
\hline May & 41.73 & 54.35 & 36.06 & 36.82 & 33.34 \\
\hline June & 45.49 & 51.99 & 37.21 & 47.74 & 31.88 \\
\hline July & 46.81 & 42.20 & 25.55 & 36.24 & 31.02 \\
\hline August & 43.28 & 45.42 & 39.01 & 40.17 & 32.11 \\
\hline September & 49.86 & 47.79 & 37.40 & 43.67 & 36.58 \\
\hline October & 49.48 & 42.76 & 38.11 & 35.90 & 30.13 \\
\hline November & 50.45 & 45.45 & 34.91 & 35.60 & 30.78 \\
\hline December & 60.50 & 33.97 & 36.86 & 28.80 & 28.99 \\
\hline
\end{tabular}


Table 15 - Monthly averaged EOC dataset, $D_{M A}$, period relative heat demand.

\begin{tabular}{|l|c|c|c|c|c|}
\hline Relative heat demand[-] & $\mathbf{2 0 1 0}$ & $\mathbf{2 0 1 1}$ & $\mathbf{2 0 1 2}$ & $\mathbf{2 0 1 3}$ & $\mathbf{2 0 1 4}$ \\
\hline January & 0.83 & 0.83 & 0.83 & 0.83 & 0.83 \\
\hline February & 0.83 & 0.83 & 0.83 & 0.83 & 0.83 \\
\hline March & 0.78 & 0.78 & 0.78 & 0.78 & 0.78 \\
\hline April & 0.62 & 0.62 & 0.62 & 0.62 & 0.62 \\
\hline May & 0.34 & 0.34 & 0.34 & 0.34 & 0.34 \\
\hline June & 0.31 & 0.31 & 0.31 & 0.31 & 0.31 \\
\hline July & 0.24 & 0.24 & 0.24 & 0.24 & 0.24 \\
\hline August & 0.30 & 0.30 & 0.30 & 0.30 & 0.30 \\
\hline September & 0.38 & 0.38 & 0.38 & 0.38 & 0.38 \\
\hline October & 0.50 & 0.50 & 0.50 & 0.50 & 0.50 \\
\hline November & 0.72 & 0.72 & 0.72 & 0.72 & 0.72 \\
\hline December & 0.82 & 0.82 & 0.82 & 0.82 & 0.82 \\
\hline
\end{tabular}


Table 16 -Seasonal averaged peak/off-peak averaged EOC dataset, $D_{S P}$, period duration.

\begin{tabular}{|l|c|c|c|c|c|}
\hline Duration [h] & $\mathbf{2 0 1 0}$ & $\mathbf{2 0 1 1}$ & $\mathbf{2 0 1 2}$ & $\mathbf{2 0 1 3}$ & $\mathbf{2 0 1 4}$ \\
\hline Winter, peak & 1440 & 1440 & 1456 & 1440 & 1440 \\
\hline Winter, off-peak & 720 & 720 & 728 & 720 & 720 \\
\hline Spring, peak & 1470 & 1470 & 1470 & 1470 & 1470 \\
\hline Spring, off-peak & 736 & 736 & 736 & 736 & 736 \\
\hline Summer, peak & 1472 & 1472 & 1472 & 1472 & 1472 \\
\hline Summer, off-peak & 736 & 736 & 736 & 736 & 736 \\
\hline Autumn, peak & 1456 & 1456 & 1456 & 1456 & 1456 \\
\hline Autumn, off-peak & 728 & 728 & 728 & 728 & 728 \\
\hline
\end{tabular}


Table 17 -Seasonal averaged peak/off-peak averaged EOC dataset, $D_{S P}$, period power price.

\begin{tabular}{|l|c|c|c|c|c|}
\hline Power price [Euro/MWh] & $\mathbf{2 0 1 0}$ & $\mathbf{2 0 1 1}$ & $\mathbf{2 0 1 2}$ & $\mathbf{2 0 1 3}$ & $\mathbf{2 0 1 4}$ \\
\hline Winter, peak & 55.11 & 51.29 & 46.21 & 40.09 & 32.95 \\
\hline Winter, off-peak & 37.58 & 35.48 & 29.29 & 28.49 & 22.15 \\
\hline Spring, peak & 45.49 & 56.95 & 37.08 & 42.97 & 31.62 \\
\hline Spring, off-peak & 33.96 & 47.97 & 28.15 & 33.94 & 24.33 \\
\hline Summer, peak & 48.85 & 50.75 & 39.44 & 46.76 & 34.01 \\
\hline Summer, off-peak & 37.87 & 37.91 & 22.78 & 30.43 & 26.98 \\
\hline Autumn, peak & 52.45 & 51.37 & 40.53 & 42.45 & 35.35 \\
\hline Autumn, off-peak & 44.88 & 33.19 & 29.42 & 30.19 & 26.71 \\
\hline
\end{tabular}


Table 18 -Seasonal averaged peak/off-peak averaged EOC dataset, $D_{S P}$, period relative heat demand.

\begin{tabular}{|l|c|c|c|c|c|}
\hline Relative heat demand[-] & $\mathbf{2 0 1 0}$ & $\mathbf{2 0 1 1}$ & $\mathbf{2 0 1 2}$ & $\mathbf{2 0 1 3}$ & $\mathbf{2 0 1 4}$ \\
\hline Winter, peak & 0.87 & 0.87 & 0.87 & 0.87 & 0.87 \\
\hline Winter, off-peak & 0.73 & 0.73 & 0.73 & 0.73 & 0.73 \\
\hline Spring, peak & 0.64 & 0.64 & 0.64 & 0.64 & 0.64 \\
\hline Spring, off-peak & 0.45 & 0.45 & 0.45 & 0.45 & 0.45 \\
\hline Summer, peak & 0.34 & 0.34 & 0.34 & 0.34 & 0.34 \\
\hline Summer, off-peak & 0.15 & 0.15 & 0.15 & 0.15 & 0.15 \\
\hline Autumn, peak & 0.62 & 0.62 & 0.62 & 0.62 & 0.62 \\
\hline Autumn, off-peak & 0.36 & 0.36 & 0.36 & 0.36 & 0.36 \\
\hline
\end{tabular}

